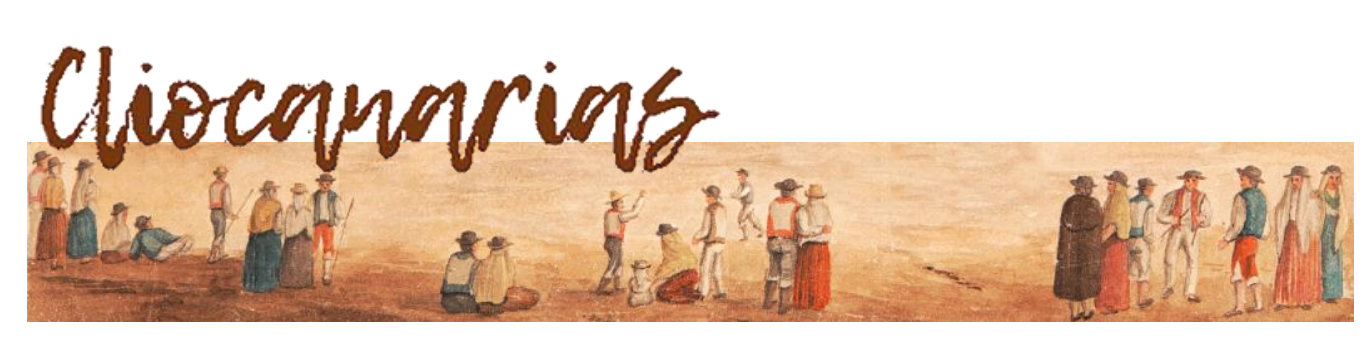

ISSN 2695-4494

https://doi.org/10.53335/cliocanarias.2021.3.11

\title{
CABEÇAS: DISSEMINAÇÃO, DESIGUALDADE E CONCENTRAÇÃO NO MERCADO DE CATIVOS (LUANDA, C. 1798-1804)
}

\author{
CABEÇAS: DISSEMINATION, INEQUALITY AND CONCENTRATION IN THE THE MAR- \\ KET FOR CAPTIVES (LUANDA, C. 1798-1804)
}

\section{Roberto GUEDES FERREIRA * Ana Paula BÔSCARO**}

Resumo: Calcado em registros paroquiais de batismos, o artigo analisa a distribuição do mercado de cativos em Luanda entre 1798 e 1804 . Contexto de grande demanda atlântica por escravos, os batismos de $c a-$ beças (adultos) demonstram que o mercado era, simultaneamente, aberto e concentrado. Ao lado de vários mercadores de poucos escravos, um reduzidíssimo número de negociantes dominava o trato de gente. Todavia, este seleto grupo de negociantes quase monopolistas era heterogêneo, posto que formado por capitães de embarcação e, sobretudo, por integrantes das elites locais luandenses e homens oriundos de outras partes da monarquia portuguesa (Brasil e Portugal). Conclui-se que a intensa atuação de diferentes grupos sociais no negócio significou que o mercado de cativos gozou de amplo respaldo político, moral e social.

PALAVRAS-CHAVES: Luanda, mercado interno de cativos, hierarquia

ABSTRACT: Based on baptismal parish records, this paper analyses the relative market share between slave traders in Luanda from 1798 to 1804 . In the context of high Atlantic demand for slaves, the baptism of cabeças (term used to refer to adult slaves destined for sale) show that the market was at the same time open and concentrated. Alongside many small-scale merchants, that sold a few slaves at a time, an extremely reduced number of large-scale traders dominated the trade in people. However, this select group of nearly monopolistic traders was heterogeneous, since it was composed of different kinds of people, including vessel captains, members of the Luanda elite and men from other parts of the Portuguese monarchy (Brazil and Portugal). The conclusion reached is that the intense participation of different social groups in the business meant that the market for captives had wide political, moral and social support.

KEYWORDS: Luanda, internal slave trade, social hierarchy

\footnotetext{
* Professor do Programa de Pós-Graduação em História Social da Universidade Federal do Rio de Janeiro. C. e.: robertoguedesferreira@gmail.com

** Doutora em História pela da Universidade Federal de Juiz de Fora. C. e.: anapaulaboscaro@gmail.com
} 


\section{Introdução ${ }^{1}$}

\section{Adultos}

Aos seis dias do mês de março de mil oitocentos e quatro batizou solenemente o reverendo coadjutor Manoel Teixeira de Carvalho quinhentas e dezenove cabeças e sete crias do coronel Anselmo da Fonseca Coutinho, de que mandei fazer este assento e assinei.

O Vigário João Pinto Machado².

A cidade de Luanda abrigou o maior porto exportador de cativos da África durante a época moderna, voltado a atender à imensa demanda da escravidão nas Américas, sobretudo do Brasil. Vindos das fronteiras de escravização da África Central Atlântica, os cativos aguardavam em Luanda antes de embarcar, tal como alhures ${ }^{3}$. Do interior para a costa e à espera agonizante do embarque, eles frequentemente eram denominados de cabeças (adultos) e crias, inclusive ao serem batizados na freguesia de Nossa Senhora dos Remédios. À margem dos batismos de cabeças, os padres da freguesia anotavam Adultos, sem que percamos de vista que um padre da paróquia vizinha, a de Nossa Senhora da Conceição, registrou o batismo de Lucrécia como o de uma adulta já de sete anos de idade ${ }^{4}$. Em termos fiscais mercantis, um alvará de 25 de janeiro de 1758 determinava que pelas crias de peito (em idade de amamentação) não se pagariam taxas, pelas crias de pé de quatro palmos para baixo (que já andavam) se cobraria metade dos direitos por cada uma, mas pelos

\footnotetext{
${ }^{1}$ Pesquisa financiada pelo Conselho Nacional de Desenvolvimento Científico e Tecnológico (CNPq), pela Coordenação de Aperfeiçoamento de Pessoal de Nivel Superior (CAPES) e Pela Fundação Carlos Chagas de Pesquisa do Estado do Rio de Janeiro (Faperj).

2 Fonte: Arquivo da Arquidiocese de Luanda (AAA), Freguesia de Nossa Senhora dos Remédios, Livro de Registro de Batismo (LBFNSR), 1802-1804, fl. 254. Doravante AAA-LBFNSR. No corpo do texto, como outras expressões coevas, utilizamos os termos adultos, cabeça ou crias a fim de compreender a percepção sobre o que à época se chamava resgate ou carregação (comércio de cativos). Nem mesmo a palavra tráfico era adota para se referir ao negócio, ao menos na documentação consultada. Agradecemos a Roquinaldo Ferreira o aceso aos batismos de Luanda.

${ }^{3}$ Sobre fronteiras da escravização e trato de cativos na Africa Central, cf. MILLER, J. C.: Way of death: Merchant Capitalism and the Angolan Slave Trade, 1730-1830. Wisconsin, Wisconsin University Press, 1988, cap. 5 e parte II; FERREIRA, R. A.: Dos Sertões ao Atlântico. Rio de Janeiro: UFRJ, PPGHIS, 1997, Dissertação de Mestrado; CURTO, J. C.: Álcool e escravos. O comércio luso-brasileiro do álcool em Mpinda, Luanda e Benguela durante o tráfico atlântico de escravos (c. 1480-1830) e o seu impacto nas sociedades da África Central Ocidental, Lisboa, Editora Vulgata, 2003, p. 343; ELTIS, D, e D. RICHARDSON (eds.): Extending The Frontiers: Essays on the New Transatlantic Slave Trade Database, New Haven, Yale University Press, 2008; CANDIDO, M. P.: An African Slaving Port and the Atlantic World: Benguela and its Hinterland. Cambridge: Cambridge University Press, 2013, cap 4; SPARKS, R. J.: Where the Negroes Are Masters: An African Port in the Era of the Slave Trade, Cambridge, Massachusetts, and London, England: Harvard University Press, 2014, cap 5.

${ }_{4}^{4}$ AAA-Freguesia de Nossa Senhora da Conceição, Livro de Registro de Batismo, 1770-1786, fl. 286.
} 
escravos adultos que ultrapassassem quatro palmos se arrecadaria o valor total de 8.700 réis por cada um $^{5}$.

Os adultos e crias remetidos por Luanda que chegaram ao outro lado do atlântico nos séculos XVIII e XIX desembarcaram, em sua maioria, no porto Rio de Janeiro ${ }^{6}$, mas nesta cidade as cabeças eram chamadas de escravos novos. A partir do Rio, os novos eram direcionados para várias partes do Brasil, principalmente para a capitania, depois província, de Minas Gerais, a do próprio Rio de Janeiro e a de São Paulo. Como já abordamos intensamente o comércio interno de cativos no Brasil a partir do porto carioca7, aqui nos ocupamos apenas da distribuição do mercado de cabeças em Luanda durante a virada do século XVIII para o XIX. Para empreender a análise, usamos, principalmente, três livros de registros de batismo da freguesia de Nossa Senhora dos Remédios que contemplam os anos de $1798^{\circ}$ a 1804 , cujas informações serão cruzadas com outros documentos de cunho administrativo e com correspondências entre autoridades.

A paróquia de Nossa Senhora dos Remédios se localizava na cidade baixa, zona portuária, e só nela houve batismo de cabeças e de crias porque, na freguesia de Nossa Senhora da Conceição, na cidade alta, zona administrativa, só se batizou crianças entre 1770 e $1786^{\circ}$. Nos anos mencionados, houve 4.604 crianças batizadas nas duas freguesias, mas elas e seus pais escravos

\footnotetext{
${ }^{5}$ Cf.: [<http:/ / www.governodosoutros.ics.ul.pt/?menu=consulta\&id_partes=105\&accao=ver\&pagina $=609>$ ]. Ver também Arquivo Histórico Ultramarino (AHU), Códice 555, fls. $12,23$.

${ }^{6}$ Sobre os portos da África Central e suas conexões com o Rio de Janeiro, cf. nota 2 e FLORENTINO, M. G.: Em Costas Negras: uma história do tráfico de escravos entre a África e o Rio de Janeiro, Rio de Janeiro: Arquivo Nacional, 1995; ELTIS, D.: The Rise of African Slavery in the Americas, Cambridge, Cambridge University Press, 2000; OLIVEIRA, M. R.: Divisão Naval da Costa d'Leste: a expansão da Guerra Cisplatina para o litoral africano (1825-1830), Seropédica, UFRRJ-PPHR. Diss. de Mestrado, 2017. Ver ainda: The Transatlantic Slave Trade Database, Voyages (TSTD). On line.

7 FRAGOSO, J., y R. GUEDES: Tráfico de escravos, mercadores e fianças. Dois bancos de dados (despachos de escravos, passaportes e licenças). Códices 390, 411, 419, 421, 424, 425, 1000 e 1002. Relatório de Pesquisa apresentado ao IPEA, 2001a; GUEDES, R.: "Comércio interno de cativos, grandes traficantes e forros traficantes: o compromisso social com a escravidão, com a desigualdade, e a precariedade de um corpus documental (Sudeste do Brasil, inícios do século XIX)", in: CURY, C. et. al (orgs.): O Império do Brasil: educação, impressos e confrontos sociopoliticos, São Luís: Café \& Lápis/Editora Uema, 2015, pp. 317-360: BÔSCARO, A. P., e R. GUEDES, R.: "Escravos tropeiros e traficantes de cativos, seus senhores, seus camaradas e seus parceiros (Sul-Sudeste do Brasil, 1809-1833)", in IVO, Isnara, Roberto GUEDES (orgs.). Escravidão: povos, poderes e legados. Américas, Goa e Angola (séculos XVIXXI). São Paulo: Alameda, 2020, pp. 279-310; 2020; BÔSCARO, A. P, e R. GUEDES: (2020a): "O Rio de Janeiro e a reprodução da sociedade escravista: rotas e agentes no comércio interno de cativos entre a corte e São Paulo (1809-1933)". Arquivo Geral da Cidade do Rio de Janeiro (org.). Escravidão e luta pela liberdade no Rio de Janeiro: histórias, arquivos e patrimônio. Rio de Janeiro: Prefeitura do Rio/AGCRJ, 2020a, pp. 21-56.

8 Seis registros foram realizados em 1797 e por serem poucos foram agregados ao ano de 1798.

9 AAA-LBFNSR, 1797-1799; 1800-1802; 1802-1804; AAA, Livro de Registro de Batismos da Freguesia de Nossa Senhora da Conceição (LBFNSC) (1770-1786).
} 
com nomes cristãos, como a adulta Lucrécia, não eram destinados ao mercado, e não serão objeto deste artigo. ${ }^{10}$ Os batismos de cabeças e crias, sim, remetiam aos inseparáveis tratos local e atlântico de cativos. Como a epígrafe deste artigo demonstra, em tais cerimônias não havia pais, padrinhos ou madrinhas nomeados. Consta apenas o nome do padre batizante, o do padre que assentava o batismo no livro, o número de cabeças e crias sem nome cristão e o nome de seus respectivos donos. Agregados, 3.888 assentos batismais da freguesia dos Remédios contemplam 52.093 cabeças e 1.593 crias, que totalizam 53.686 cativos batizados entre março de 1798 e junho de 1804 (cerca de seis anos e três meses), e doravante aludiremos apenas às cabeças que eram a imensa maioria, mas nelas incluídas as crias.

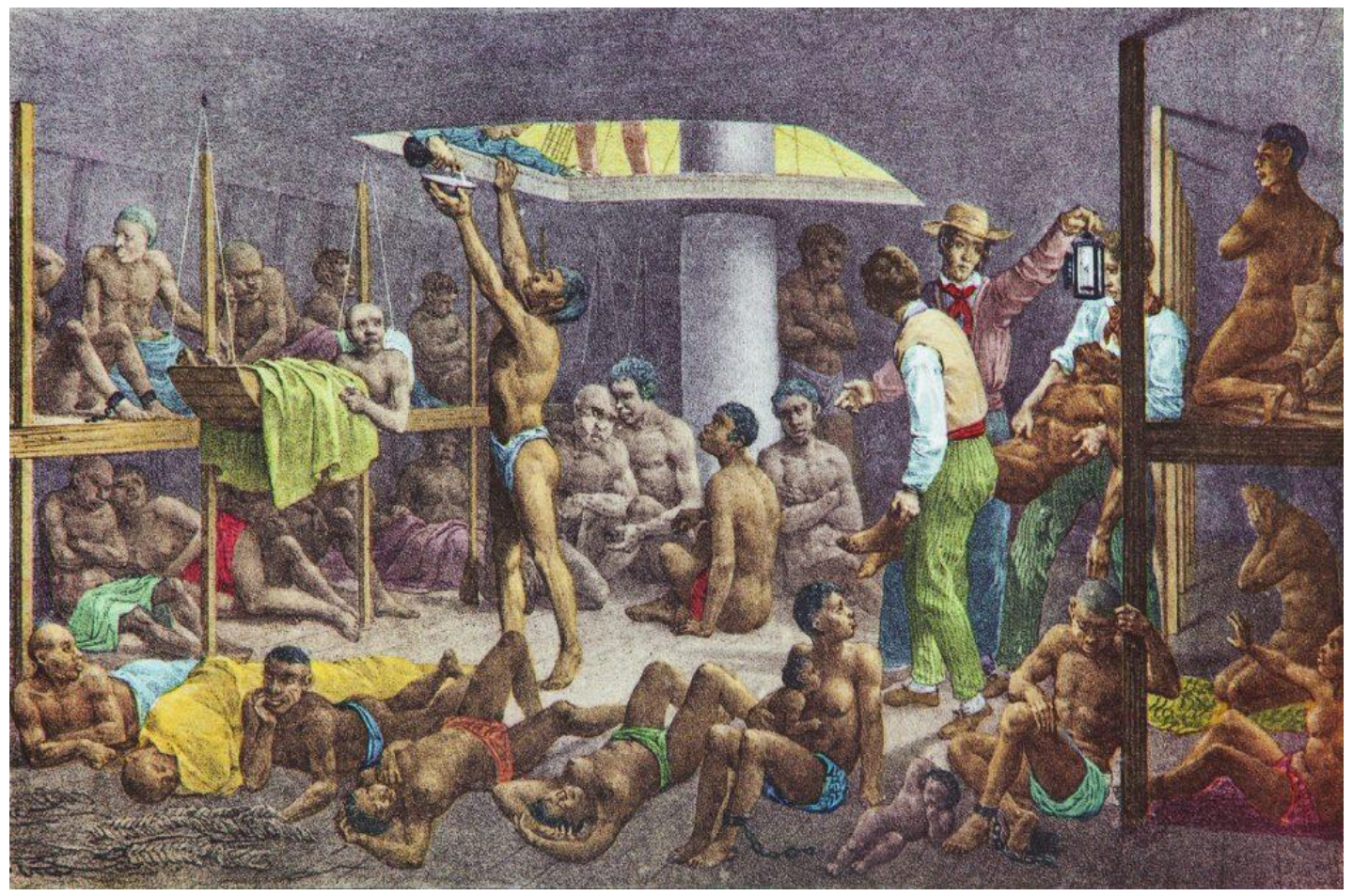

Por Johann Moritz Rugendas, Escravos negros no porão do navio, 1835.

O estudo dos batismos de cabeças se insere no clássico tema do comércio interno e atlântico de cativos africanos. Todavia, a dimensão do negócio no porto de Luanda ainda é pouco perscrutada, ainda que os fluxos local e atlântico fossem inseparáveis. Daí que pretendemos avançar na análise do mercado local pelo uso inédito de registros de batismo de cabeças para este fim porque tais documentos são uma amostragem significativa do número cativos e de

$10 \mathrm{Cf}$. as diferenças entre batismos de cabeças e de crianças com nome cristão em FERREIRA, R. A., e R. GUEDES: "Erasing the note that says slave. Efigênia da Silva, baptism, compadrazgo, names, heads, crias, slave trade, slavery and freedom (Luanda, c. 1770-c. 1811)", Almanack, 2020 Sobre batismos de crianças em Angola e Benguela, ver também THORNTON, J. K.: "Central African names and African-American naming patterns", William and Mary Quarterly, Williamsburg, v. 50, n. 4, 1993, pp. 727-742; CURTO, J. C.: "As if from a free womb: baptismal manumissions in the Concepcion Parish, Luanda, 1778-1807". Portuguese Studies Review, [s. 1.], v. 10, n. ${ }^{\circ}$ 1, 2002, pp. 26-57; CANDIDO, M. P.: "African women in ecclesiastical documents, Benguela, 1760-1860", Social Sciences and Missions, Leiden, v. 28, n. os 3-4, 2015, pp. 235-260; OLIVEIRA, V. S.: The Donas of Luanda, c. 1770-1867: from Atlantic slave trading to "legitimate" commerce, Toronto, York University, Dissertation (Doctor of Philosophy), 2016. 
negociantes. Por eles pode-se perguntar, por exemplo: quantas pessoas participavam do trato? Como se dividiam as fatias do mercado de cabeças às vésperas do embarque? Quem eram os principais comerciantes?

Ressaltamos, no entanto, que há lacunas no corpus documental, uma vez que os batismos não registram todos os comerciantes da cidade e nem todas as cabeças embarcadas em Luanda, posto que são registros de uma época pré-estatística ${ }^{11}$. Igualmente, não sabemos se os donos das cabeças operavam por si, por terceiros e/ou em parcerias mercantis, e tampouco é possivel aferir as fontes de financiamento etc. Não obstante, os documentos paroquiais propiciam uma oportunidade impar para averiguar a distribuição do mercado de cativos porque informam o número de cabeças batizadas e o nome de seus donos. Por eles, portanto, podemos saber algo mais sobre a comunidade mercantil da cidade e sobre as diferentes formas de participação na atividade.

Com efeito, várias pessoas de distintos grupos sociais atuaram no negócio, ainda que tenha imperado uma enorme concentração do mercado ${ }^{12}$. Destarte, além de estimular a escravização, a mercancia de gente hierarquizou o corpo mercantil luandense porque o acesso ao mercado de cativos era muito desigual. Entrementes, proporcionalmente, veremos, muitos moradores da cidade comerciaram gente. A intensa presença de diferentes segmentos sociais significa que a disseminação do comércio de escravos expressava a aceitação social da escravização, do próprio negócio e da desigualdade social entre livres. Assim, o negócio era democrático, no sentido de acessivel a diferentes grupos sociais. Mas, igualmente, o comércio de humanos distinguia os livres. Tal como uma sociedade escravista diferenciava os livres ao criar uma elite calcada e reproduzida a partir da renda extraida do trabalho escravo ${ }^{13}$, o comércio de gente, parte componente de uma sociedade escravista, também moldava o ordenamento social porque também o hierarquizava. Aliás, no caso de Luanda e o do chamado reino de Angola ${ }^{14}$, o processo de escravização e o comércio de cativos não visavam, primordialmente, reproduzir a escravidão local, ainda que também o fizessem decisivamente, mas vender cativos para o Brasil. Muito mais cativos foram remetidos pelo Atlântico do que escravizados localmente. Por conseguinte, o trato de gente era mais do que a mera troca de mercadorias por cativos, tendo em vista que ele também formou uma espécie

\footnotetext{
${ }_{11}$ MARCÍLIO, M. L.: Crescimento demográfico e evolução agrária paulista (1700-1836). São Paulo: Hucitec, 2000.

12 MILLER, J. C.: Way of death: Merchant..., op. cit., capítulo 6.

13 FINLEY, M.: Escravidão antiga e ideologia moderna, Rio de Janeiro: Graal, 1991.

${ }^{14}$ WEBER, P. M.: "Angola" como conceito: uma análise da obra história geral das guerras angolanas Oliveira de Cadornega (século XVII). Porto Alegre: PUC-RS, Programa de Pós-Graduação em História, tese de doutorado, 2018.
} 
de modus vivendi social traficante naturalizado. O negócio, ainda que hierarquizante, não incomodava ninguém, ou quase ninguém ${ }^{15}$, porque uma andorinha não faz verão ${ }^{16}$. Ao contrário, de diferentes maneiras e com distintas possibilidades de participação, vivia-se dele e para ele.

Não havia contradição no fato de o comércio de humanos ser concentrado e gozar de respaldo social entre diversos grupos, na medida em que sua aceitação se deveu, antes, à sua própria abertura a distintos setores sociais, como já se constatou para o Brasilit. Mesmo no pós-Independência do Brasil em 1822, Angola, sob administração colonial portuguesa, e com forte estímulo do recém-estado independente brasileiro, prosseguiu intensamente com o negócio, com tendência crescente até a abolição oficial do comércio de cativos no mesmo Brasil, em 185018. Assim, respaldado política e institucionalmente, cada pessoa e/ou família livre (ou forra), associações e grupos mercantis, instituições leigas ou religiosas, etc., tomou parte como pôde. Em sintese, o comércio de cativos em um dos pontos nodais, Luanda, do cross-cultural exchange, do fluxo e do refluxo entre África e Brasil pelo rio chamado Atlântico ${ }^{19}$, se assentou, também, no aval político, social e moral de que desfrutou ${ }^{20}$.

Vistos o objeto, o documento base e a perspectiva que servem à investigação, divide-se a exposição em dois momentos. No primeiro, afere-se a divisão e as formas de acesso ao mercado de cabeças batizadas, depois passamos aos participantes do negócio.

\section{De uma a 519 cabeças e sete crias}

No dia 6 de março de 1804, de uma só vez um padre batizou 519 cabeças e sete crias do coronel Anselmo da Fonseca Coutinho, como se constata na epí-

\footnotetext{
15 Para outras searas e épocas, entre outros, ver: MEMEL-FÔTE, H.: L'esclavage dans les sociétés lignagères de l'Afrique noire. Exemple de la Côte d'Ivoire précoloniale, 1700-1920. Thèse (pour le doctorat d'État ès lettres et sciences humaines). Paris: École des Hautes Etudes en Sciences Sociales, 1988; STILWELL, S. : Slavery and Slaving in African History. Cambridge: Cambridge U. P., 2014; SPARKS, R.: Where the Negroes Are Masters: An African..., op. cit. 16 MEILLASSOUX, C.: Antropologia da escravidão: o ventre de ferro e o dinheiro, Rio de Janeiro: Zahar, 1996.

17 FRAGOSO, J., e R. GUEDES: "Alegrias e artimanhas de uma fonte seriada. Os códices 390, 421, 424 e 425: despachos de escravos e passaportes da Intendência de Polícia da Corte, 1819-1833", BOTELHO, T. et al (orgs.): História Quantitativa e serial no Brasil: um balanço. Goiânia: ANPUH-MG, 2001; BÔSCARO, A. P.: Sociedade Traficante: o comércio interno de escravos no centro-sul brasileiro e suas conexões na primeira metade do século XIX (Juiz de Fora, Minas Gerais), Juiz de Fora, Programa de Pós-Graduação em História, Tese de Doutorado, 2021, caps. 2 e 4.

18 FLORENTINO, M. G.: Em Costas Negras: uma história..., op. cit.; FERREIRA, R.: CrossCultural Exchange in the Atlantic world: Angola and Brazil during the era of the slave trade. Cambridge: Cambridge U. P., 2012; OLIVEIRA, M. R.: Divisão Naval da Costa..., op. cit.; MAMIGONIAN, B. G.: Africanos Livres: a abolição do tráfico de escravos no Brasil. São Paulo: Companhia das Letras, 2017.

19 VERGER, P.: Fluxo e refluxo do tráfico de escravos entre o Golfo de Benin e a Bahia de Todos os Santos. São Paulo: Corrupio, 1987; FERREIRA, R.: Cross-Cultural Exchange..., op. cit.; COSTA e SILVA, A.: Um rio chamado Atlântico. A África no Brasil e o Brasil na África, Rio de Janeiro: UFRJ/Nova Fronteira, 2003.

20 Sobre questões morais do tráfico e da escravidão, cf. ainda DAVIS, D. B.: O problema da escravidão na cultura ocidental. Rio de Janeiro: Civilização Brasileira, 2000.
} 
grafe. O luandense Coutinho era um dos maiores comerciantes de cativos estabelecidos na cidade entre fins do século XVIII e inícios do século XIX, tendo sido responsável por $5 \%$ de todos os cativos embarcados em Luanda entre 1768 e $1806^{21}$, indice próximo dos $7 \%$ das cabeças batizadas de que era dono entre 1798 e 1804. Ele estava no topo do ranking dos vendedores de humanos. Havia outros como ele, mas a grande maioria era de envergadura bem mais modesta.

Apesar da concorrência no trato de humanos e da relativa dificuldade de se manter no negócio ${ }^{22}$, os registros de batismo informam 1.071 diferentes nomes de proprietários de cabeças na freguesia dos Remédios ${ }^{23}$. Naqueles pouco mais de seis anos, este milhar de comerciantes equivaleria a quase $1 / 3$ da população livre luandense de 1804 (ver quadro 1), população na qual se incluem mulheres e crianças, ausentes dos batismos como donos de cabeças, salvo meia dúzia de mulheres ${ }^{24}$. Este grande contingente de participantes constata a abertura do mercado a homens como o coronel Coutinho, que fez batizar 3.778 cabeças, mas também acessivel a um marinheiro dono de seis cabeças, ao preto Camossanda, proprietário de uma, tal como o cabo esquadra de apelido Cahengo ${ }^{25}$, entre tantos outros pequenos donos. Portanto, grandes negociantes partilhavam cotas do negócio com vendedores eventuais, similar a Annamaboe, por exemplo26.

Aparentemente, a forma de acesso e o ritmo dos batismos variavam conforme a chegada dos cativos vindos do interior em Luanda e/ou de acordo com a iminência da partida dos navios para as Américas. Por exemplo, no dia 20 de novembro de 1771, o governador de Angola, Francisco Inocêncio de Sousa Coutinho, escreveu uma carta ao capitão mor do presídio (uma unidade administrativa, militar e mercantil interiorana) de Ambaca ordenando que avisasse a todos os correspondentes do comerciante Matias da Costa que, até o dia 15 de dezembro, remetessem para Luanda todas as cabeças que puderem

${ }^{21}$ SILVA, D. B. D. : "The Supply of Slaves from Luanda, 1768-1806: Records of Anselmo da Fonseca Coutinho", African Economic History, v. 38, p. 55, 2010.

22 MILlER, J. C.: MILlER, J. C.: Way of death: Merchant..., op. cit.; SILVA, D. B. D.: "The Supply of Slaves from Luanda...". art. cit., pp. 53-76.

${ }^{23}$ Excluem-se deste número os nomes ilegiveis e com margem a dúvidas para identificação. Também, se o nome fosse muito comum, a exemplo de João da Silva, ele foi desconsiderado. Há 195 nomes perdidos que abrangem 999 cabeças. O intenso cruzamento de fontes auxiliou a identificação.

${ }^{24}$ Sobre a participação de mulheres no comércio de cativos, cf. CAPELA, J.: Donas, Senhores e Escravos. Porto: Afrontamento, 1996; CARDOSO, C. A. L.: "Ana Joaquina dos Santos Silva: Industrial Angolana da segunda metade do século XIX", in Boletim Cultural da Câmara Municipal de Luanda, v. 32, 1972, p. 5-14; PANTOJA. S.: "Gênero e comércio: as traficantes de escravos na região de Angola", Travessias. Revista de Ciências Sociais e Humanas em Língua Portuguesa, n. 4/5, Lisboa, 2004; BERGER, I.: "African Women's History: Themes and perspectives", Journal of Colonialism and colonial History, Baltimore, v. 4, n. ${ }^{\circ}$ 1, 2003, pp. 1-11; Ana Joaquina dos Santos Silva: Industrial Angolana da segunda metade do século XIX, in Boletim Cultural da Câmara Municipal de Luanda, v. 32, pp. 5-14; WHEELER, D. L.: "Angolan Woman of Means: D. Ana Joaquina dos Santos e Silva, Mid-Nineteenth Century Luso-African Merchant-Capitalist of Luanda", in Santa Barbara Portuguese Studies Review, v. 3, 1996, pp. 284-297.

${ }^{25}$ AAA-LBFSNR, 1800 a 1802, pp. 134, 202v, 268v.

26 SPARKS, R. J.: Where the Negroes Are Masters: An African..., op. cit., cap. 5. 
para a expedição de um seu navio ${ }^{27}$. Nota-se, assim, que havia uma rede organizada de informações entre as cidades costeiras (Luanda e Benguela) e os presídios do interior voltada a suprir, com a maior celeridade possivel, as embarcações em iminentes viagens ao Atlântico. O porto de Luanda, portanto, apressava o ritmo de fornecimento de cabeças vindas do interior, leia-se, estimulava o ritmo da escravização.

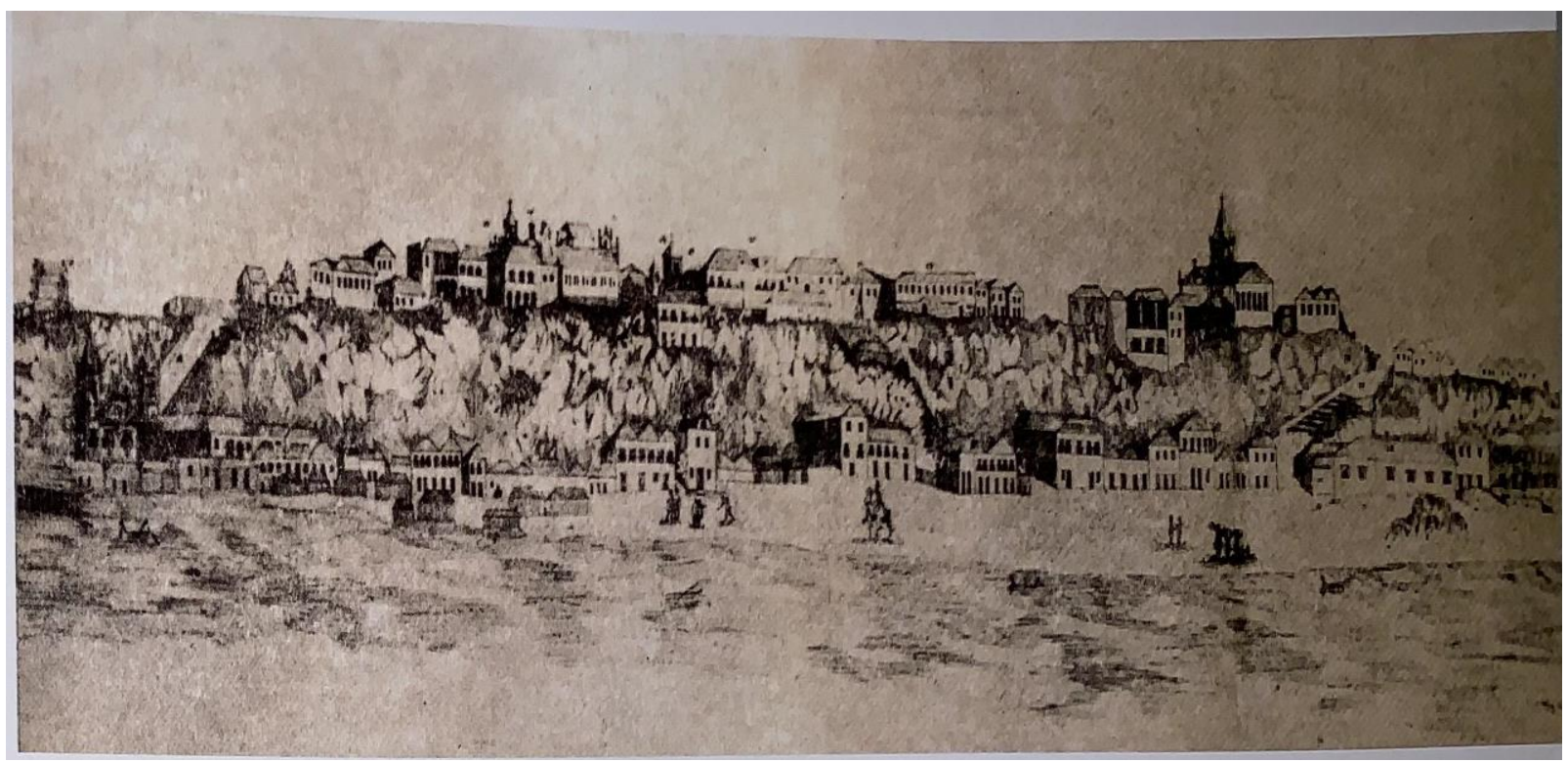

Prospecto da Cidade de São Paulo e Assunção, 1808.

Fonte: Sociedade de Geografia de Lisboa, Cota 6/0/10.

No entanto, havia transações mercantis que demoravam mais do que o desejado, revelando outras facetas do circuito africano até o embarque rumo ao Brasil. No dia 1 de dezembro do mesmo ano de 1771, o mesmo governador enviara uma carta ao capitão mor de Benguela, porto ao Sul de Luanda, ordenando que tomasse medidas a respeito de um navio do capitão Domingos Furtado de Mendonça. O governador mandou o capitão mor zelar pelo navio porque disse saber que o sócio de Mendonça lhe insinuava levar 800 cabeças, 500 próprias e 300 da praça ${ }^{28}$; da praça quer dizer de outros comerciantes atuantes no local. A transação em Benguela lhe pareceu injusta e prejudicial a Mendonça porque a demora do navio neste porto traria risco à equipagem $\mathrm{e}$ à armação, perda de cativos por mortes e prejuizo à arrecadação da fazenda real portuguesa. O governador alegou que, enquanto a embarcação estava estacionada, duas outras zarparam antes em vantagem, o que prejudicou o capitão Mendonça.

Sendo assim, as palavras do governador demonstram que o acesso às cabeças postas nos navios dependia das remessas interioranas consignadas aos mercadores nos portos. Sem suas cotas completas de cabeças, o navio de Mendonça esperou, enquanto outros passaram à sua frente, furando a fila. Para tentar superar este empecilho e favorecer Mendonça, o governador justificou

27 AHA, Códice 80, c. de fl. 12 e fl. 42. Não há numeração original.

28 Idem. 
sua ordem ao capitão mor pelo afeto que dedicava a Mendonça e pelo muito zelo com seus bens ${ }^{29}$. O governador Sousa Coutinho confirma que o afeto e os elos pessoais interferiam no suprimento de cativos e no ritmo das partidas das embarcações, afetos e laços sabidamente fulcrais para o funcionamento das redes mercantis de cativos em Angola ${ }^{30}$. Logo, o mercado de adultos sem nomes cristãos nas cidades portuárias de embarque não era baseado exclusiva e principalmente na lei da oferta e da procura ${ }^{31}$.

Sousa Coutinho desejava que o navio do capitão Mendonça zarpasse ainda naquele ano 1771. Se não saísse por falta de cabeças, o capitão mor de Benguela deveria auxiliá-lo. Porém esta ajuda não poderia ser feita com o abuso da ambição de extorquir mais e mais cabeças da praça e o capitão mor também deveria ser um pouco mais indulgente com os escravos dos marinheiros. Se não fosse de mercadorias próprias, a embarcação não poderia levar mais de 50 praças [cabeças] da gente da mareação ${ }^{32}$. Transferindo-o ao capitão mor, o dilema do governador era favorecer seu amigo Mendonça sem prejudicar os marinheiros e os mercadores da praça de Benguela.

Com ou sem solução, o dilema de Sousa Coutinho revela que havia distintas possibilidades de obtenção de cativos nas cidades portuárias, que até redundavam em extorsões e competição por cativos nas praças mercantis de embarque. Mas uma cota para a marinhagem devia ser respeitada. O documento não especifica o número de marinheiros tripulantes, todavia, fosse como fosse, as cabeças que chegavam às cidades litorâneas eram distribuídas desigualmente entre diferentes participantes do negócio, desde os grandes comerciantes até os marinheiros. Pelo exposto, tudo indica que açabarcar cabeças em Luanda dependia, em parte, da capacidade de captar o fornecimento de cativos vindos do interior e de se afeiçoar nas praças locais. Até a cota da marinhagem e, decerto, as de outros pequenos mercadores, estavam relacionadas a tais fatores.

Como marinheiros, capitães e outros mercadores locais recebiam e embarcavam seus respectivos cativos no porto de Luanda, os padres da freguesia de Remédios, que ganhavam emolumentos por cabeças batizadas ${ }^{33}$, identificaram 1.071 diferentes donos, cujas oportunidades desiguais de acesso ao mercado se evidenciam nos batismos que contavam com apenas uma cabeça, no mínimo, até as 519 cabeças e sete crias pertencentes a Anselmo da Fonseca Coutinho, no máximo. ${ }^{34}$

\footnotetext{
29 Idem.

30 THOMPSOM, E.: Famílias traficantes nas rotas entre Angola e Brasil em fins do século XVIII, Brasília: UNB, Programa de Pós-Graduação em História, Dissertação de mestrado, 2006; PANTOJA, S.: "Laços de afeto e comércio de escravos. Angola no século XVIII", Cad. Pesq. Cdhis, Uberlândia, v. 23, n. ${ }^{\circ}$ 2, jul./dez., 2010.

${ }^{31}$ POLANYI, K.: A grande transformação, Rio de Janeiro: Campus, 2002.

${ }^{32}$ Idem.

${ }^{33}$ Arquivo Histórico Ultramarino, Avulsos de Angola (doravante AHU), Cx. 66, doc. 92.

34 Decerto entre os participantes ocasionais havia comerciantes de porte avultado. Porém, entre os 676 donos cujos nomes só constam uma vez, 364 (53,9\%) só venderam uma única cabeça cada um, $178(26,3 \%)$ entre dois e cinco cativos, e apenas $11(1,6 \%)$ alienaram mais de 50 .
} 
Contudo, apesar da disparidade, eram muitíssimas as cabeças batizadas por causa do grande número de participantes no trato de adultos na cidade $\mathrm{e}$ da altíssima demanda nas Américas.

\section{Representatividade das cabeças}

Para que se tenha uma ideia do volume de cabeças adultas batizadas em Luanda, cumpre relacioná-lo com a própria população luandense, com os cativos exportados e com os desembarcados nas Américas. Pelo quadro 1, notase que havia mais cativos exportados pela cidade do que pessoas (livres ou escravas) nela residentes entre 1798 e 1804. Destarte, os adultos exportáveis formavam o grosso da população luandense, porém eles eram um contingente passageiro, ainda que permanente na paisagem da urbe. Luanda era, antes de tudo, um local de trânsito forçado, e, pela própria magnitude do fluxo perene de cativos, vários grupos sociais lidaram com o comércio de gente, pois alimentar as cabeças, mantê-las em quintais, conduzi-las aos navios etc. comprometia uma série de agentes sociais. Como esta enorme população mercadejada era constantemente presente, no ano de 1798, por exemplo, apenas as cabeças batizadas somadas (não o total de cativos exportados) equivaleram a $87,8 \%$ do total dos habitantes da cidade, ou a quase o dobro da população livre, e também ultrapassaram o contingente escravo residente. Salvo em 1804, ano em que só há batismos entre os meses de janeiro e junho, as cabeças excediam as populações livre ou escrava, cada uma isoladamente (quadro 1). Destarte, para os moradores livres da cidade, era quase inescapável não estar de algum modo atado ao mercado de gente.

Os adultos batizados na freguesia de Nossa Senhora dos Remédios também equivalem a proporções significativas dos cativos exportados por Luanda e dos desembarcados no maior porto americano de fins do século XVIII, o Rio de Janeiro. Entre os anos de 1798 e 1803, as cabeças batizadas compunham de $66,8 \%$ a $89,7 \%$ do total de cativos exportados pela cidade africana. Em reelação aos desembarques no porto carioca entre 1798 e 1803, nunca menos de $70 \%$ das cabeças batizadas teriam aportado no Rio, chegando mesmo a superar o número de cativos desembarcados neste cais (quadro 1). Evidentemente, o número de adultos batizados em Luanda podia estar aquém do de africanos arribados no Rio porque esta urbe não recebia apenas escravos saídos desta praça mercantil africana. Por outro lado, as cabeças também foram para outros portos das Américas nos anos em que elas superaram os escravos chegados à praça carioca ${ }^{35}$.

\footnotetext{
35 Sobre o comércio com outras cidades brasileiras, cf. CANDIDO, M.: An African Slaving..., op. cit.; CARVALHO, M. J. M.: "O desembarque nas praias: o funcionamento do tráfico de escravos depois de 1831", in Revista de História (USP), v. 167, 2012, pp. 223-260; XIMENES, C. F L.: Bahia e Angola: redes comerciais e o tráfico de escravos (1750-1808). Niterói. UFFPPGHIS, Tese de Doutorado em História, 2012; ALBUQUERQUE, A. E. B.: De "Angelo dos retalhos" a visconde de Loures: a trajetória de um traficante de escravos (1818-1858), Recife: UFPE-PPGHIS, Dissertação de Mestrado, 2016.
} 


\section{Quadro 1}

Estimativas da população residente, de cativos exportados e número de cabeças e crias batizadas (Luanda, 1798-1804)

\begin{tabular}{|c|c|c|c|c|c|c|c|c|c|c|c|c|c|}
\hline \multirow{3}{*}{ 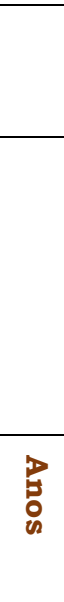 } & \multicolumn{6}{|c|}{ 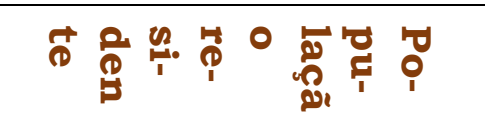 } & \multirow{3}{*}{ 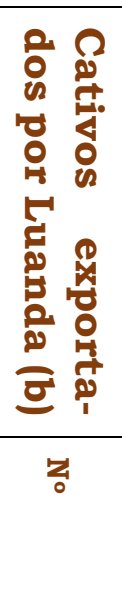 } & \multirow{2}{*}{\multicolumn{3}{|c|}{ 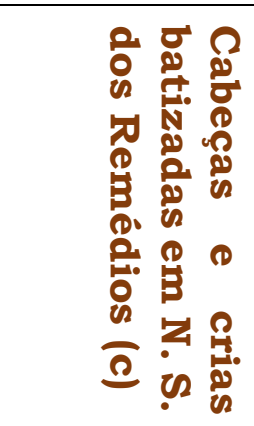 }} & \multirow{3}{*}{ 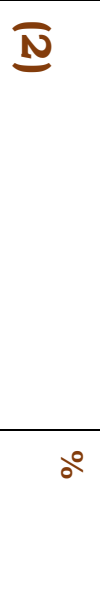 } & \multirow{3}{*}{$\begin{array}{c}\text { w) } \\
\circ\end{array}$} & \multirow{3}{*}{ 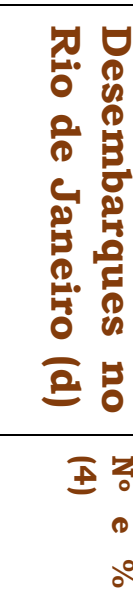 } \\
\hline & \multicolumn{2}{|c|}{$\begin{array}{l}\text { 旨 } \\
\underset{4}{4} \\
0 \\
0\end{array}$} & \multicolumn{2}{|c|}{ 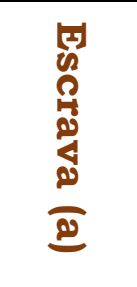 } & \multicolumn{2}{|c|}{ 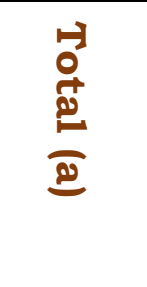 } & & & & & & & \\
\hline & 경 & $\diamond_{*}^{\circ}$ & 경 & $\stackrel{\circ}{\circ}$ & 경 & $\stackrel{\circ}{\Xi}$ & & 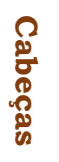 & $\stackrel{8}{8}$ & 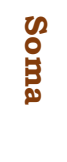 & & & \\
\hline $\begin{array}{l}\varpi \\
0 \\
\infty\end{array}$ & $\begin{array}{l}\omega \\
\dot{\sigma} \\
\stackrel{\omega}{\sigma}\end{array}$ & $\begin{array}{l}\vec{c} \\
\text { cr }\end{array}$ & $\begin{array}{l}+ \\
\dot{\omega} \\
\text { o } \\
N\end{array}$ & $\begin{array}{l}0 \\
+ \\
+\infty \\
+\infty\end{array}$ & $\begin{array}{l}\infty \\
\dot{\omega} \\
\omega\end{array}$ & $\begin{array}{l}1 \\
\text { ŏ } \\
0\end{array}$ & $\begin{array}{l}\overrightarrow{0} \\
\dot{0} \\
\dot{p}\end{array}$ & $\begin{array}{l}a \\
\infty \\
\infty \\
0 \\
0\end{array}$ & $\begin{array}{l}\text { No } \\
\text { O }\end{array}$ & $\begin{array}{l}v \\
\dot{d} \\
0 \\
0\end{array}$ & $\begin{array}{l}2 \\
\infty \\
\infty\end{array}$ & $\begin{array}{l}\infty \\
\stackrel{\infty}{\infty} \\
. \infty\end{array}$ & 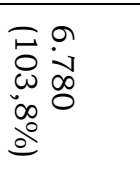 \\
\hline ث્ & $\begin{array}{l}\omega \\
\dot{\vec{U}} \\
\text { ज़ }\end{array}$ & $\stackrel{\vec{b}}{\stackrel{b}{\bullet}}$ & $\begin{array}{l}\omega \\
\dot{N} \\
\alpha \\
+\end{array}$ & $\begin{array}{l}\text { O } \\
0 \\
0\end{array}$ & $\begin{array}{l}\stackrel{a}{+} \\
\stackrel{+}{+}\end{array}$ & مै & $\begin{array}{l}\infty \\
\dot{\omega} \\
\dot{0} \\
\perp\end{array}$ & $\begin{array}{l}\stackrel{a}{\omega} \\
\stackrel{\omega}{N}\end{array}$ & $\stackrel{\vec{v}}{\mathrm{v}}$ & $\begin{array}{l}\stackrel{a}{ } \\
\dot{a} \\
\stackrel{\omega}{ }\end{array}$ & $\begin{array}{l}\text { I } \\
\text { O }\end{array}$ & $\underset{\infty}{\infty}$ & 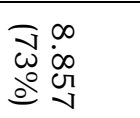 \\
\hline $\begin{array}{l}\ddot{\infty} \\
\varnothing \\
0\end{array}$ & ' & ' & I & 1 & ' & ' & $\begin{array}{l}\infty \\
\dot{\vec{b}} \\
0\end{array}$ & $\begin{array}{l}. v \\
0 \\
0 \\
+\end{array}$ & $\stackrel{N}{N}$ & $\begin{array}{l}v \\
\text { v } \\
\text { v }\end{array}$ & $\begin{array}{l}\infty \\
\stackrel{0}{0}\end{array}$ & ' & 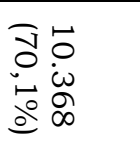 \\
\hline$\stackrel{\infty}{\infty}$ & ' & ' & ' & ' & ' & ' & $\begin{array}{l}\overrightarrow{0} \\
\dot{\vec{t}} \\
0\end{array}$ & 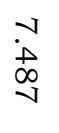 & $\underset{\infty}{\omega}$ & $\begin{array}{l}\stackrel{v}{ } \\
\dot{\infty} \\
\dot{+}\end{array}$ & $\begin{array}{l}\text { J } \\
\text { O }\end{array}$ & ' & $\begin{array}{l}\overline{0} \\
0 \\
0 \\
0 \\
0\end{array}$ \\
\hline $\begin{array}{l}\infty \\
\stackrel{\infty}{N} \\
\stackrel{0}{N}\end{array}$ & $\begin{array}{l}+ \\
\dot{0} \\
\dot{\omega}\end{array}$ & 언 & $\begin{array}{l}N \\
\infty \\
\omega \\
N \\
N\end{array}$ & $\begin{array}{l}+ \\
0 \\
0\end{array}$ & $\begin{array}{l}a \\
i \\
N \\
\mathcal{U}\end{array}$ & $\begin{array}{l}c r \\
\text { c } \\
\infty\end{array}$ & $\begin{array}{l}\vec{\sigma} \\
\dot{0} \\
\stackrel{\infty}{0}\end{array}$ & $\begin{array}{l}\overrightarrow{0} \\
\dot{\vec{D}}\end{array}$ & $\begin{array}{l}\omega \\
\stackrel{\omega}{\omega}\end{array}$ & $\begin{array}{l}\text { ○ } \\
\dot{\leftrightarrow} \\
\stackrel{\omega}{N} \\
N\end{array}$ & $\begin{array}{l}\infty \\
-1 \\
0\end{array}$ & 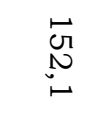 & 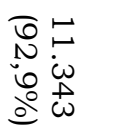 \\
\hline $\begin{array}{l}\infty \\
\infty \\
\infty\end{array}$ & $\begin{array}{l}\omega \\
\text { in } \\
\text { oे }\end{array}$ & $\begin{array}{l}\mathrm{G} \\
\stackrel{\sim}{\mathrm{G}}\end{array}$ & $\begin{array}{l}\omega \\
\dot{\omega} \\
\dot{\omega} \\
\pm\end{array}$ & $\begin{array}{l}\infty \\
\infty \\
c r\end{array}$ & $\begin{array}{l}0 \\
i \\
0 \\
\ddots\end{array}$ & $\begin{array}{l}\stackrel{\infty}{\infty} \\
\stackrel{N}{N}\end{array}$ & $\begin{array}{l}\overrightarrow{\vec{D}} \\
\dot{\omega} \\
\overrightarrow{\mathrm{N}}\end{array}$ & $\stackrel{\varphi}{\underset{\nu}{\supset}}$ & $\underset{N}{N}$ & $\begin{array}{l}0 \\
\dot{0} \\
\infty \\
\infty\end{array}$ & $\begin{array}{l}9 \\
0 \\
\infty\end{array}$ & $\underset{\substack{c \\
\omega \\
0}}{\vec{D}}$ & 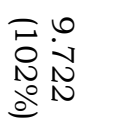 \\
\hline $\begin{array}{l}\infty \\
\infty \\
\infty \\
\perp\end{array}$ & $\begin{array}{l}\omega \\
\dot{\omega} \\
\stackrel{\infty}{v}\end{array}$ & $\stackrel{c}{\sigma}$ & $\begin{array}{l}\dot{\omega}_{\dot{\omega}} \\
\omega_{N}\end{array}$ & $\begin{array}{l}\vec{D} \\
\infty \\
\omega\end{array}$ & $\begin{array}{l}a \\
\dot{\omega} \\
\tilde{\sigma}\end{array}$ & $\begin{array}{l}\vec{b} \\
\stackrel{G}{N}\end{array}$ & $\begin{array}{l}\vec{\omega} \\
\dot{\vec{b}} \\
\infty\end{array}$ & $\begin{array}{l}+ \\
\text { in } \\
\stackrel{1}{+}\end{array}$ & ป & $\stackrel{\vec{a}}{\dot{\omega}}$ & 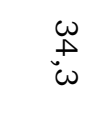 & $\begin{array}{l}0 \\
0 \\
\infty\end{array}$ & 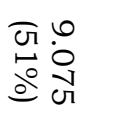 \\
\hline
\end{tabular}

Fonte: (a) CURTO, J e GERVASIS, R. (2001, pp. 50,58); (b) CURTO, J. (2002, p. 343); (c) AAA-LBFNSR, 1797-1799, 1800-1802, 1802-1804; (d) FLORENTINO, M. G (1995, p.59).Legenda:

* Percentuais entre populações livre e escrava residentes;

(1) Percentuais da população luandense em relação ao número de cativos exportados por Luanda;

(2) Percentuais de cabeças e crias em relação ao número de cativos exportados por Luanda;

(3) Percentuais de cabeças e crias em relação ao número total da população luandense;

(4) Percentuais de cabeças e crias em relação ao número total de cativos desembarcados no Rio de Janeiro. 
Não há dados populacionais de Luanda para os anos de 1800 e 1801.

Para efeito de ajuste de cálculo, seis batismos de cabeças em outubro de 1797, que totalizam 127 cativos, foram agregados ao ano de 1798. O ano de 1804 só contempla batismos entre os meses de janeiro e junho.

Em sintese, pela sua grandeza e representatividade, os batismos de cabeças são um indicador confiável da distribuição do mercado de cativos em Luanda, igualmente porque nesta cidade o batismo foi mais orientado pela exportação de adultos do que pela salvação das almas de crianças, ao menos em termos de número de batizados, ainda que a preocupação da igreja católica fosse, além dos emolumentos por cabeças batizadas ${ }^{36}$, salvar, pelo sacramento batismal, as almas das cabeças cristãmente inominadas que miseravelmente morriam ao atravessavam o Atlântico ${ }^{37}$. A propósito, o batismo de cabeças sequer foi previsto na legislação canônica que orientava o modo de realizar o sacramento e redigir os assentos ${ }^{38}$.

\section{O mercado desigual de cabeças: fornecimento e distribuição}

O grosso dos adultos era batizado no varejo. No total de 3.888 registros de batismo de adultos, a maioria (não absoluta) não contemplou mais de uma cabeça por cerimônia. Assim, houve 1.156 (31, 3\%) sacramentos com apenas uma cabeça, que, porém, açambarcaram somente $2,2 \%$ dos cativos batizados. Aliás, todos os $2.527(57,4 \%)$ registros com até 10 cabeças formavam a maioria dos assentos, mas não abocanharam sequer $10 \%$ dos cativos. Por sua vez, no atacado, as cerimônias, agrupadas, com mais de 20 cativos, que eram apenas $20,1 \%$, agregaram 74,3 \% das cabeças. Em grandes cerimônias coletivas -178 (4,8 \%) batismos com entre 51 e 100 cabeças- abençoou-se 23,7 \% de todas as almas em Nossa Senhora dos Remédios (quadro 2).

Esta forma predominante do batismo varejista sugere o fornecimento também varejista no mercado interno africano no sentido do interior, ou mesmo

36 AHU, Cx. 66, doc. 92.

37 Segundo o governador de Angola D. João Manuel de Noronha (1713-1717), iam-se cabeças por alto nos navios, excedendo a capacidade de suas arqueações, acedendo assim a muita mortandade. Isto gerava descaminhos da Real Fazenda e outros prejuizos não de menor importância porque não iam catequizadas as cabeças que se embarcam por alto. Muitos cativos partiam por batizar, mas morrendo pelo grande aperto e sem baptismo perdem suas almas, enquanto outros homens perdiam a liberdade por lhes embarcarem sendo forros. Biblioteca Pública de Évora, Seção de Reservados, BPE, Secção dos Reservados, Cod. CXVI / 2-15, n. ${ }^{\circ}$ 11, fl. 29. É pouco provável que tal cenário tenha mudado em fins do século XVIII.

38 A elaboração dos registros de batismo foi regulamentada pelas Constituições Primeiras do Arcebispado da Bahia, publicadas em 1720, cujas normas canônicas valiam para Luanda. VIDE, Sebastião Monteiro da (1720). Constituições Primeiras do Arcebispado da Bahia, Coimbra, Real Colégio das Artes e da Companhia de Jesus, Livro Primeiro, Títulos IX ao XX, Brasil, Brasília, Edição do Senado Federal, 2007. Sobre a diocese de Angola e Congo, sufragânea à Arquidiocese da Bahia entre 1672 e 1845, vide SANTOS, M. E. M. África; «Angola", in AZEVEDO, C. M. de (dir.): Dicionário de história religiosa de Portugal. Lisboa: Círculo de Leitores, 2000, pp. 21-25, 51-67. Ver ainda MARCUSSI, A.: "O dever catequético: a evangelização dos escravos em Luanda nos séculos XVIII e XVIII", Revista 7 Mares, Niterói, n. ${ }^{\circ} 2$, 2013, pp. 64-79; REGINALDO, L: "Rosários dos pretos, "São Benedito de Quissama": irmandades e devoções negras no mundo atlântico (Portugal e Angola, século XVIII)", Studia Historica, História Moderna, v. 38, n. ${ }^{\circ} 1,2016$, pp. 123-151. 
de áreas litorâneas, para o porto de Luanda, ainda que houvesse fluxos com muitos cativos. Por exemplo, em uma carta enviada ao governador de Angola em 12 de fevereiro 1799, o regente do presídio de Novo Redondo (localizado quase a meio caminho entre o porto de Luanda e o de Benguela ${ }^{39}$ ) o informava, entre outras coisas, que, em 15 de janeiro do mesmo ano, uma embarcação levou consigo oito cativos novos que remeteu José da Costa Batista a seu armador (credor), o sargento mor Antônio José de Faria. O bergantim também levou 29 cativos, nove enviados por Dona Josefa Francisca Ferreira a Guilherme José Ferreira, dez de Francisco Fernandes que consigna ao seu armador, coronel Anselmo da Fonseca Coutinho, seis que remeteu José de Nazaré a Antônio Rodrigues dos Santos, e quatro do mestre da própria embarcação ${ }^{40}$. Como se percebe, os aviados (que despachavam escravos a partir dos presídios e feiras interioranos) enviavam as cabeças em consignação ou em pagamento a seus aviantes (credores) estabelecidos em Luanda, mas eram remessas com poucos cativos. Entre os mencionados recebedores estabelecidos em Luanda, Antônio José de Faria, Guilherme José Ferreira e o já conhecido Anselmo da Fonseca Coutinho constam entre os maiores donos de cabeças batizadas na freguesia dos Remédios (quadro 4 no apêndice), mas até eles auferiram cativos saídos do interior chegados à conta gotas na cidade.

Igualmente, na saída para o Atlântico, até os maiores mercadores de humanos lidavam com o varejo na maneira de distribuí-los. Eles não punham todos os cativos no mesmo barco a fim de diminuir riscos de perdas, como naufrágios etc. ${ }^{41}$.

Assim, os maiores comerciantes também abasteciam os navios em pequenas remessas, mas, diferente dos eventuais, faziam-no de modo perene e, muito provavelmente, contavam com um leque maior de aviados. Então, talvez por causa de tais aspectos logísticos e da própria participação diferenciada de vários mercadores, o batismo com 519 cabeças e sete crias do coronel Anselmo da Fonseca Coutinho, em março de 1804, foi uma exceção que confirma a tendência de concentração de poucos batismos no atacado concomitante ao batismo varejista. Mas é óbvio que as 971 cabeças de Coutinho batizadas em 1804 não embarcaram em um mesmo navio ao rumo ao Atlântico porque neste ano houve ao menos 34 partidas da cidade realizadas por 29 diferentes navios (TSTD).

\footnotetext{
39 O fluxo de cativos entre Benguela e Luanda era corrente. Por exemplo, em 1798, 1.130 escravos de Benguela para Luanda, e a escala em Novo Redondo devia ser obrigatória. Projeto Acervo Digital Angola-Brasil (Padab) desenvolvido entre o Arquivo Histórico de Angola (AHA) e o Instituto Histórico e Geográfico Brasileiro (IHGB), Códice 256-C-11-3 Imagens (Img) 370372. Doravante, as referências aos documentos, disponiveis no IHGB, oriundos deste convênio serão abreviadas como Padab.

40 Padab, Códice 256-C-11-3, Img. 423.

${ }^{41}$ SILVA, D. B. D.: "The Supply of Slaves...", art. cit.
} 
Quadro 2

Cabeças e crias por batismo

(Freguesia de Nossa Senhora dos Remédios, 1798-1804)

\begin{tabular}{|c|c|c|c|c|}
\hline \multirow{2}{*}{\begin{tabular}{|l|} 
Cabeças e/ou \\
Crias por batismo \\
No
\end{tabular}} & \multicolumn{2}{|c|}{ Batismos } & \multicolumn{2}{|c|}{$\begin{array}{l}\text { Total de Cati } \\
\text { vos }\end{array}$} \\
\hline & No & $\%$ & No & $\%$ \\
\hline 1 & 1.156 & 31,3 & 1.156 & 2,2 \\
\hline 2 & 452 & 12,2 & 904 & 1,7 \\
\hline 3 & 242 & 6,6 & 726 & 1,4 \\
\hline 4 & 156 & 4,2 & 624 & 1,2 \\
\hline 5 & 113 & 3,1 & 565 & 1,1 \\
\hline Subtotal de 1 a 5 & 2.119 & 57,4 & 3.975 & 7,5 \\
\hline De 6 a 10 & 408 & 11,0 & 3.176 & 6,0 \\
\hline De 11 a 20 & 427 & 11,6 & 6.407 & 12,2 \\
\hline De 21 a 50 & 497 & 13,5 & 16.004 & 30,4 \\
\hline De 51 a 100 & 178 & 4,8 & 12.482 & 23,7 \\
\hline De 101 a 200 & 54 & 1,5 & 7.460 & 14,2 \\
\hline Mais de 200 & 10 & 0,2 & 3.183 & 6,0 \\
\hline Total & 3.693 & 100,0 & 52.687 & 100,0 \\
\hline
\end{tabular}

Fonte: AAA-LBFNSR, 1797-1799, 1800-1802, 1802-1804

O modo de batizar, em resumo, era extremamente concentrado, no atacado, em poucos batismos, mas em sua base prevaleceu o varejo perene, indicando os fluxos e os ritmos das chegadas de cativos do interior. Indica, também, o provimento constante, feito capilarmente por distintos mercadores, das embarcações no porto da cidade, o que vigorou em concomitância com grandes levas de cativos fornecidos de uma só vez aos negreiros.

Mais importante, as distintas, mas cotidianas, maneiras de dar cerimônia às cabeças, fossem estas muitas ou poucas, revelam que a cidade era, de fato, parte de uma sociedade traficante ${ }^{42}$ atlântica comprometida até o pescoço com a compra e venda de gente, uma vez que todos negociassem: varejistas eventuais, grandes tratantes atacadistas, capitães de navios, marinheiros, homens, algumas mulheres, donas, militares de alta patente, soldados, civis, forros, brancos, pretos, pardos, solteiros, casados, viúvas, padres, entre outros. Não havia fronteiras ocupacionais, de qualidade de cor (preto, branco, pardo etc.) ou de sexo que fossem um obstáculo intransponivel à participação no negócio. Bastava ser livre ou forro (e talvez até cativo residente na cidade).

\footnotetext{
${ }^{42}$ A expressão é de BÔSCARO, A. P.: Sociedade Traficante: o comércio interno..., op. cit.
} 
Contudo, havia a elite e os homens do topo que quase monopolizavam a posse das cabeças.

\section{A elite e o topo: donos das cabeças}

Antônio José da Silva Lisboa estava no cume entre os mercadores de gente porque mandou batizar quase cinco mil cabeças entre 26 de março de 1798 a 3 de junho de1804. Na base da pirâmide estavam os vendedores ocasionais (que batizaram até 10 adultos), respectivamente seguidos por pequenos (entre 11 e 50), médios (entre 51 e 300), grandes (entre 301 e 700), elite (entre 701 e 1.000 ) e os do topo (mais de 1.000) (quadro 3).

Refletindo a hierarquia do negócio, a média de cabeças nos batismos de Antônio José da Silva Lisboa, 43,3, era muito acima da média da grande maioria dos demais vendedores de gente (quadro 3). Destarte, a par do amplo compromisso moral, político e social para com o comércio de pessoas, o mercado era concentradíssimo nas mãos de menos de uma dúzia de homens, os verdadeiros donos do negócio. Nesse sentido, a elite mercadora de cativos, que era de apenas cinco pessoas / famílias $(0,5 \%)$, respondeu por mais cabeças vendidas (4.034) do que os 767 comerciantes ocasionais (2.002 cabeças) ou os 170 pequenos (4.006 cabeças), cada um destes isoladamente. No sentido inverso, quanto mais se ia do topo à base, mais o negócio se disseminava. No alicerce da pirâmide, o grosso dos negociantes, os 364 que batizaram apenas uma cabeça, era formado por $34 \%$ dos vendedores, grupo que alienou apenas 0,7 $\%$ dos cativos (quadro 3).

Juntados, todos os 767 ocasionais e 170 dos pequenos (apenas os pequenos com até 20 cabeças) representavam 87,5 \% dos vendedores, porém só controlavam 26,2 \% das cabeças. Parte substancial deles era composta por oportunistas ocasionais, especialmente os que alienaram até 10 adultos, porque neste grupo somente $21 \%$ realizou mais de um batismo. Pode até ser que nem todas as cabeças cativas dos donos desta faixa de ocasionais se destinassem ao trato atlântico, mas à realimentação da escravidão na própria cidade de Luanda. Na verdade, os participantes ocasionais estavam aquém até dos pequenos vendedores. A média de escravos alienados era substancialmente maior entre os pequenos e a frequência ao mercado também, pois $62,4 \%$ deles batizaram cabeças mais de uma vez. Já entre os ocasionais a esmagadora maioria (79 \%) só mandou realizar um ato batismal.

Sintetizando, a hierarquia no negócio de cativos na cidade não era apenas entre os do topo e os da base; era escalonada. Um indicador desta direção é o fato de a proporção de comerciantes que efetivou mais de um batismo tender a aumentar a partir do grupo de pequenos vendedores, atingindo $100 \%$ entre os que comerciaram mais de 200. Isto permite afirmar, não obstante os batismos de cabeça aqui avaliados só contemplem pouco mais de seis anos, que determinados donos de cabeças eram grandes atacadistas e contumazes frequentadores do mercado de Luanda, como se detalhará adiante. 
Quadro 3. Distribuição do mercado local de cabeças batizadas em Luanda (1798-1804)

\begin{tabular}{|c|c|c|c|c|c|c|c|c|c|c|}
\hline \multirow[t]{2}{*}{\begin{tabular}{l} 
Nú- \\
mero \\
de ca- \\
beças \\
batiza- \\
das \\
\multicolumn{1}{c}{ No }
\end{tabular}} & \multicolumn{2}{|c|}{ Donos } & \multicolumn{2}{|c|}{$\begin{array}{l}\text { Donos com } \\
\text { mais de um } \\
\text { batismo no } \\
\text { grupo }\end{array}$} & \multicolumn{3}{|c|}{$\begin{array}{c}\text { Totais de Cabeças } \\
\text { Batizadas }\end{array}$} & \multicolumn{2}{|c|}{$\begin{array}{l}\text { Totais de } \\
\text { Batismos }\end{array}$} & \multirow[t]{2}{*}{\begin{tabular}{|l|} 
Mé- \\
dia \\
de \\
Ca- \\
beças \\
por \\
Ba- \\
tismo \\
\multicolumn{1}{|c|}{ No $^{\circ}$} \\
\end{tabular}} \\
\hline & No & $\%$ & No & $\%$ & No & $\%$ & Média & No & $\%$ & \\
\hline 1 & 364 & 34,0 & - & & 364 & 0,7 & 1,0 & 364 & 9,9 & 1,0 \\
\hline 2 a 3 & 217 & 20,3 & 76 & 35,0 & 496 & 0,9 & 2,3 & 304 & 8,2 & 1,6 \\
\hline 4 a 5 & 82 & 7,7 & 45 & 54,9 & 363 & 0,7 & 4,4 & 169 & 4,6 & 2,1 \\
\hline 6 a 10 & 104 & 9,7 & 44 & 42,3 & 799 & 1,5 & 7,7 & 203 & 5,5 & 3,9 \\
\hline $\begin{array}{l}\text { Entre } 1 \text { e } \\
10 \text { (Oca- } \\
\text { sionais) }\end{array}$ & 767 & 71,6 & 165 & 21,5 & 2.022 & 3,8 & 2,6 & 1.040 & 28,2 & 1,9 \\
\hline 11 a 20 & 84 & 7,8 & 44 & 52,4 & 1.226 & 2,3 & \begin{tabular}{|l|}
14,6 \\
\end{tabular} & 223 & 6,0 & 5,5 \\
\hline 21 a 50 & 86 & 8,0 & 62 & 72,1 & 2.780 & 5,3 & 32,3 & 329 & 8,9 & 8,4 \\
\hline $\begin{array}{l}\text { Entre } 11 \\
\text { e } 50 \text { (Pe- } \\
\text { quenos) }\end{array}$ & 170 & 15,9 & 106 & 62,4 & 4.006 & 7,6 & 23,6 & 552 & 15,0 & 7,3 \\
\hline 51 a 100 & 42 & 3,9 & 34 & 81,0 & 2.920 & 5,5 & 69,5 & 239 & 6,5 & 12,2 \\
\hline 101 a 200 & 38 & 3,5 & 36 & 94,7 & 5.332 & 10,1 & 140,3 & 298 & 8,1 & 17,9 \\
\hline 201 a 300 & 16 & 1,5 & 16 & 100,0 & 3.892 & 7,4 & 243,3 & 257 & 7,0 & 15,1 \\
\hline \begin{tabular}{|lr} 
Entre & 51 \\
e & 300 \\
(Médios)
\end{tabular} & 96 & 9,0 & 86 & 89,6 & 12.144 & 23,1 & 126,5 & 794 & 21,5 & 15,3 \\
\hline 301 a 500 & 18 & 1,7 & 19 & 100,0 & 6.109 & 11,6 & 339,4 & 386 & 10,5 & 15,8 \\
\hline 501 a 700 & 9 & 0,8 & 9 & 100,0 & 5.157 & 9,8 & 573,0 & 242 & 6,6 & 21,3 \\
\hline $\begin{array}{l}\text { Entre } \\
301 \text { e } 700 \\
\text { (Grandes) }\end{array}$ & 27 & 2,5 & 27 & 100,0 & 11.226 & 21,3 & 415,8 & 628 & 17,0 & 17,9 \\
\hline $\begin{array}{l}\text { Entre } \\
701 \\
1.000 \\
\text { (Elite) }\end{array}$ & 5 & 0,5 & 5 & 100,0 & 4.034 & 7,7 & 806,8 & 196 & 5,3 & 20,6 \\
\hline \begin{tabular}{|ll} 
Mais de \\
1.000 \\
(Topo)
\end{tabular} & 6 & 0,6 & 6 & 100,0 & 19.203 & 36,5 & $3.200,5$ & 481 & 13,0 & 39,9 \\
\hline \begin{tabular}{|l|} 
Total \\
\end{tabular} & 1.071 & 100 & 395 & 36,9 & 52.675 & 100 & 49,2 & 3.691 & 100,0 & 14,3 \\
\hline
\end{tabular}

Fonte: AA-LBFNSR, 1797-1799, 1800-1802, 1802-1804.

Obs: Exclui casos com margem a dúvidas de leitura.

Os mercadores do topo e da elite, que eram apenas 11 pessoas $(1,1 \%$ dos donos), aglutinaram nada mais nada menos do que 23.237 (44,2\% do total) 
cabeças batizadas naqueles pouco mais de seis anos. É como se naquele curto período tivessem alienado quase três vezes toda a população luandense de 1798 ou um pouco mais da metade da população urbana da cidade do Rio de Janeiro de 179943 . Repita-se: 11 homens em apenas pouco mais de seis anos. Imediatamente abaixo do topo e da elite, estava o grupo dos grandes comerciantes, responsável pela remessa de 21,3\% das cabeças. Estres três grupos (grande, elite e topo), que abrangem 38 (3,6\%) mercadores, abocanharam, em resumo, 65,5 \% do mercado. Eis os privilegiados do mercado de gente. Salvo o já conhecido Coutinho ${ }^{44}$ quem eram eles? Como operavam?

Antes de tudo, não formavam um grupo homogêneo, em termos de envergadura, naturalidade, formas de operação etc. No entanto, é possivel agrupálos, apesar das lacunas da documentação, em dois grandes tipos: de um lado, os filhos da terra (naturais de Angola) e os estabelecidos (brasileiros ou portugueses) e, de outro, os capitães de embarcação. Ainda que a informação sobre naturalidade seja escassa na documentação consultada, parte dos estabelecidos foi assim considerada porque ocupou postos militares locais (ordenança, auxiliar ou de linha) e/ou cargos na administração civil por determinado tempo, pelo menos três anos, mas chegando a mais de 20. Decerto, tal divisão não esgota outras tipologias e tampouco significa segmentações entre os mercadores ou homogeneidade em cada grupo. Trata-se, apenas, para efeito de explanação, de uma percepção a partir dos resultados alcançados pelo cruzamento de fontes, nomeadamente registros de batismo, correspondências administrativas e o rol de nomes de capitães de embarcações oriundo do TSTD. dice)

5.1 Os capitães de embarcações (ver detalhes e fontes no quadro 4 no apên-

Paulino Pinto da Mota, o $10^{\circ}$ colocado em número de cativos do quadro 4 , era um experiente capitão de navios que transitava entre portos da África Central Atlântica e do Sudeste do Brasil. Em 1793, capitaneou a corveta Cabo Frio (nome colonial e ainda atual de uma cidade do estado do Rio de Janeiro), que partiu do porto de Santos, na capitania de São Paulo, Brasil, retornando, depois de se abastecer de cativos em Luanda, para a própria cidade de Santos com escala no Rio de Janeiro. Paulino Pinto da Mota não devia ser o dono da corveta e de suas mercadorias, uma vez que, em 1797, ele não era proprietário do navio Ana de Lisboa, que também apenas capitaneava. O casco e as mercadorias no valor de 49.051\$, 610 pertenciam à firma lisboeta Manoel Joseph de Sousa Freire e Companhia. O Ana Lisboa partiu da capital lusa por volta de agosto de 1797 para comprar cativos em Cabinda, Molembo, Loango e mais portos do Norte de Luanda. Porém, sem conseguir ir à costa Norte, o navio arribou avariado em Luanda em 30 de outubro do mesmo ano. Em 1799, o dono do Ana Lisboa ainda pedia ao governador de Angola isenção do pagamento de direitos reais, em Luanda, sobre as fazendas da Índia, porque já os

\footnotetext{
43 Sobre população do Rio, ver KARASCH, M.: A vida dos escravos no Rio de Janeiro (18081850), São Paulo, Cia das Letras, 2000, pp. 109, 110, 111.

${ }^{44}$ SILVA, D. B. D.: "The Supply of Slaves...", art. cit.; PANTOJA. S.: "Entre Luanda e Rio de Janeiro: o padre, o bispo e o coronel». Ibid e THOMPSON, E. C. Em torno de Angola: narrativas, identidades e as conexões atlânticas. São Paulo: Intermeios, 2014, pp. 87-109.
} 
pagara em Lisboa 45 . Os registros de batismos da freguesia dos Remédios dão conta de que o capitão Paulino Pinto da Mota batizara 737 cabeças entre 26 de março e 3 de novembro de 1798, provavelmente negociando apenas como capitão e não como principal dono das mesmas. Ele era um transportador de cativos cujos proprietários eram estabelecidos nos portos de Lisboa, de Santos e do Rio de Janeiro. Decerto, associava-se para receber seu quinhão em cabeças.

Entre os 12 capitães de navios, não há nenhum integrante do topo e apenas dois da elite. Ainda que não seja possível saber se os cativos batizados eram de fato seus ou quais eram suas partes no negócio, o fato de não estarem no topo não significa que fossem desimportantes. Sua média de adultos por batismo foi de 21,6, próxima a dos filhos da terra e 22 estabelecidos, 24,7.

Assim, ainda que os batismos não contemplem todas as cabeças dos capitães e/ou de seus credores do Brasil ou de Angola e Benguela e nem todo o período de suas atividades em Luanda, eles são uma boa amostra. Por exemplo, Antônio José Rodrigues Chaves operou na corveta Nossa Senhora da Conceição em 1793 e 1794 e, provavelmente, no bergantim Caridade, em 1803, e na corveta São Domingos Estrela, em 1808, entre outros navios. De uma só vez, em dezembro de 1803, Chaves batizou 191 cabeças em Luanda, mesmo ano de partida do bergantim Caridade desprovido de informação sobre número de escravos. Entre 1793 e 1810, Chaves fez ao menos 17 viagens capitaneando diferentes embarcações, sobretudo no circuito mercantil Rio-Luanda-Rio, com passagens ocasionais por Benguela e, no Brasil, por Pernambuco. Ele atravessou 5.453 cabeças pelo atlântico em 17 anos, contingente equivalente a $82 \%$ da população de Luanda em 1804. Em média, ele carregou 320 cativos por ano. Apenas no mês de novembro de 1798, mandou batizar 151 cabeças, ou seja, os batismos constituem uma amostra representativa dos cativos mercadejados e da importância dos capitães de navio no trato de gente.

João Inácio Coelho foi o mais iminente capitão tido por dono de cabeças batizadas na freguesia de Nossa Senhora dos Remédios, 911. Os batismos ocorreram entre 31 de março de 1800 e 25 de julho de 1803, cerca de 39 meses, pouco mais de três anos a uma média de 303 cabeças por ano. Porém, ainda em 1791 ele transportou 343 cativos para Bahia, de onde partira para Luanda. Em 1800, ele capitaneou a embarcação S. Domingos Diligente no trajeto mercantil que se iniciou na Bahia, passou em Luanda para se abastecer de cativos que, por fim, desembarcaram no Rio de Janeiro. Coelho também atuou na ilha de Santa Helena de onde novamente levou escravos para a Bahia, em 1806. Foram, pelo menos, 15 anos de participação no trato de gente.

A longevidade dos capitães de embarcações, que durou três décadas, por exemplo, no caso de Francisco Correia Garcia, condiz com o retorno favorável que estes homens tiraram do negócio. Eles, ainda que nem sempre fossem os principais donos das cabeças que transportavam, dos cascos e das mercadorias de seus navios, receberam o seu quinhão, sendo reconhecidos entre os grandes e até entre a elite mercadora de cabeças em Luanda. Mas não eram do porte dos filhos da terra e dos estabelecidos.

45 AHU, Cx. 89, doc. 49. 
5.2. Os filhos da terra e os estabelecidos (ver detalhes e fontes no quadro 4 no apêndice)

Exceto o cirurgião mor Manoel da Cruz, a elite e o topo eram compostos por homens que desfrutavam de patentes militares locais que demonstram suas inserções social, econômica e politica na cidade e nos presídios do interior, e em Benguela, provavelmente com negócios também nos portos ao Norte de Luanda, como Loango, Melmbo, Cabinda, Ambriz etc. Salta à vista os altos postos militares de coronel e sargento mor, mas os capitães e tenentes, como Ricardo da Silva Rego, também eram de famílias cujos membros se distribuíam entre a (alta) oficialidade militar em Luanda e/ou nos presídios. Como já se sabe pela historiografia ${ }^{46}$, e pelas anteriores palavras do governador Sousa Coutinho sobre o capitão mor de Benguela e o de Ambaca, militares, em geral, e capitães mores, em particular, eram centrais no processo de produção de cativos. Valiam-se de seus cargos para atuar no mercado de cabeças de Angola.

Não há possibilidade de analisar detalhadamente aqui todos os filhos da terra e estabelecidos, fossem eles grandes, da elite e do topo, mas alguns insights são viáveis a partir de exemplos de alguns deles. O capitão Antônio José da Silva Lisboa fez batizar 4.871 cabeças em 112 batismos, uma média de 43,5 cabeças por sacramento. Seus cativos foram vendidos em um interregno de cerca de seis anos e dois meses, entre 26 de março de 1798 e 3 de junho de 1804. A grandeza do aporte mercantil de Silva Lisboa se manifesta no fato de ele ser dono de $9 \%$ do total de cabeças batizadas. Os 4.871 cativos que levou ao batismo representariam, por exemplo, contingente maior do que a população livre de Luanda de 1802. Silva Lisboa, se mantivesse o ritmo de seu negócio, poderia vender todos os habitantes livres da cidade do ano de 1802 a cada seis anos, aproximadamente.

A sua estatura não se observa apenas em relação à população de Luanda, uma vez que aquelas 4.871 cabeças vendidas por este único comerciante correspondem a $48 \%$ dos cativos desembarcados no Rio de Janeiro em 1800 (quadro 1), a 32,5\% da população escrava de todas as freguesias urbanas desta mesma cidade em 1799, ou a 55,3 \% de todo seu contingente alforriado $^{47}$. Destarte, o perfil do capitão Silva Lisboa simboliza a extrema concentração do mercado de cabeças em Luanda. Em maior ou menor grau, ele expressa o grupo dos homens de negócio do topo e da elite.

46 COUTO, C.: Os capitães-mores em Angola no século XVIII. Lisboa: Instituto de Investigação Científica de Angola, 1972; SANTOS, C. M.: Um governo polido para Angola, Lisboa/Paris: UNL/EHESS, Tese de Doutorado, 2005; CARVALHO, A.: Militares e militarização no Reino de Angola: patentes, guerra, comércio e vassalagem (segunda metade do século XVIII, Seropédica, Universidade Federal Rural do Rio de Janeiro, Programa de Pós-Graduação em História, Dissertação de Mestrado em História, 2014; CARVALHO, A.: Guerras nos sertões de Angola: sobas, guerra preta e escravização (1749-1797), Rio de Janeiro: UFRJ, PPGHIS, Tese de doutotorado, 2020.

47 Sobre população do Rio, ver KARASCH, M.: A vida dos escravos no Rio de Janeiro..., op. cit., pp. 109, 110, 111 . 
Silva Lisboa já frequentava o porto de Benguela, e provavelmente também o de Luanda, desde 1787, pelo menos. Em 1790 fora alçado ao posto de capitão de uma das companhias de ordenança da barra do rio Kwanza, rio que era um importantíssimo ponto de escoamento, até a cidade de Luanda, de cativos vindos dos presídios de Muxima, Massangano, Ambaca, etc. Em 1791, caso não seja um homônimo, Silva Lisboa foi descrito como capitão e mestre de duas corvetas que levavam para a cidade de Lisboa mapas de história natural feitos por Joaquim José da Silva e oficios do governador de Angola remetidos ao secretário de estado da marinha e ultramar pottuguês. Faria escala em Pernambuco $^{48}$, para onde certamente levava cabeças que batizara em Luanda, onde deve ter falecido, como coronel, por volta de $1815^{49}$.

Pelo exposto, o capitão Silva Lisboa se ligava a rotas vindas do interior do continente africano pelo Kwanza, onde devia ter seus aviados, e prestava serviço ao governador de Angola e ao poder central em Lisboa, similarmente ao coronel Anselmo da Fonseca Coutinho e a outras famílias cujos membros ocupavam postos militares em Luanda, Benguela e nos presídios, como os Pereira Bravo ${ }^{50}$.

A diferença em relação a Silva Lisboa, ao que parece, é que Fonseca Coutinho, dono de uma galera, era um filho da terra oriundo de uma família cujos antepassados estariam em Angola pelo menos desde inícios do século XVIII, sendo, talvez por isso mesmo, muito mais ligado a redes interioranas do trato interno junto a sobados, e em Benguela, nos quais frequentemente os grandes comerciantes de cativos de Luanda se aparentavam ${ }^{51}$. Por isso, com recursos próprios Coutinho, coronel em Luanda e no presídio de Massangano, se ofereceu para armar uma ofensiva contra corsários franceses que em 1799 atrapalhavam seus negócios em Benguela. Logo, sua área de atuação era bastante ampla nos chamados reinos de Angola e de Benguela. Junto a ela, um provável seu parente, homônimo de seu pai, Antônio da Fonseca Coutinho, também integra o rol de presumiveis naturais de Angola, ocupando o posto de capitão de uma das companhias de Luanda.

Os filhos da terra e os estabelecidos tinham arimos, isto é, propriedades rurais nos vales, sobretudo dos rios Kwanza e Bengo, e alhures, a fim de abastecerem a capital e decerto alimentarem suas próprias cabeças a serem negociadas. Nesse sentido, Anselmo Coutinho se assemelha a Ricardo da Silva Rego, o $4 .^{\circ}$ mercador em número de escravos do apêndice, também dono de um arimo, onde criava gado. De longa data, ainda que nem tanto quanto os Fonseca Coutinho, os Silva Rego também comerciavam com base em uma rede familiar, ocupando, sobretudo, os postos de alferes, capitão e coronel do terço de auxiliares de Luanda, entre 1779 e 1796. Em 1770, José da Silva Rego,

\footnotetext{
48 Cf. TSTD, Nomes de Capitães de Navios; AHU, Cx. 76, doc. 86.

${ }^{49}$ Arquivo Nacional da Torre do Tombo (ANTT), Microfilme 132.

50 SILVA, D. B. D.: "The Supply of Slaves...", art. cit.; FERREIRA, R.: Cross-Cultural Exchange..., op. cit., pp. 92-94.

51 SILVA, D. B. D.: "The Supply of Slaves...", art. cit.; PANTOJA. S.: "Familias e comércio de escravos: Angola século XVIII", Cadernos de Pesquisa do CDHIS (UFU. Impresso), v. I, 2010a, pp. 23-42; ORIOLI, J. P.: "Trajetórias, mobilidade social e comércio no Atlântico no século XVIII: o padre angolano Lourenço da Costa de Almeida e seus familiares". Temporalidades, Revista de História, 2018.
} 
provável parente de Ricardo, vendeu mercadorias para um barco da fazenda real e João da Silva Rego era reconhecido, em 1782, como negociante da praça de Luanda. Um sobrinho de Paulo da Silva Rego, este também listado no quadro 4, assentou praça como ajudante (cargo militar) no presídio interiorano de Pedras do Encoge em 1794. Por outro lado, nenhum Silva Rego figura como capitão de navio no banco de dados do TSDT ${ }^{52}$. Ao que tudo indica, a base da empreitada familiar girava em torno do fluxo do interior para a cidade de Luanda. Parece que não atuavam na travessia atlântica.

Por aparentemente não atuarem na travessia atlântica, estes Silva Rego naturais e/ou estabelecidos em Angola diferem do lisboeta Antônio Rodrigues de Moura. Em 28 de dezembro de 1795, Moura foi reconhecido como homem rico e negociante da praça de Luanda, mesmo ano em que recebeu a confirmação régia do posto de capitão de um dos regimentos da capital, depois de ter sido, por dez anos, soldado, cabo de esquadra de cavalaria e tenente do regimento de infantaria auxiliar. Por volta de fevereiro de 1798, já como sargento mor do terço de ordenanças da cidade, e em vista da iminência da partida do bergantim Palma, pediu e recebeu licença do governador para viajar, por dois anos, aos portos do Rio de Janeiro e quaisquer outros do Brasil e de Portugal, se necessário lhe fosse, para o bem de suas negociações. Acompanhado do pardo forro Gaspar de Freitas, em fins de abril de 1798 saiu do Rio para Lisboa, onde nascera e era casado. Vivia em Angola há 17 anos. Em 13 de junho de 1798 registrou-se o batismo de suas primeiras cabeças na freguesia de Nossa Senhora dos Remédios. No ano seguinte, em fevereiro de 1799, ele estava de volta a Luanda, onde era negociante estabelecido, com uma carregação de fazendas avultada para dispor ou empregar o produto em escravos, ou outro qualquer gênero do pais. Pretendia, porém, retornar a Lisboa aonde com mais vantagens podia ir para terras estrangeiras, como por toda a Europa, América e Ásia, tudo em aumento da sua casa e família, e não menos dos reais direitos de Vossa Majestade.

Em resumo, Antônio Rodrigues de Moura era um mercador estabelecido com conexões imperiais, similar a outros homens da monarquia portuguesa. ${ }^{3}$ Por isso meso, ele continuou a batizar cabeças na freguesia de Nossa Senhora dos Remédios até fevereiro de 1804.

Por sua vez, o também português reinol Manoel da Cruz, 5. ${ }^{\circ}$ lugar em escravos do quadro 4, deve ter, como Moura, feito ou ampliado sua fortuna com o comércio de gente em Luanda. Em 9 de fevereiro de 1784, ele estava em Salvaterra dos Magos, Portugal, e dois dias depois foi nomeado para o cargo de cirurgião do reino de Angola. Solicitou isenção de taxas de cartas emitidas pela chancelaria ao alegar seus limitados meios. Em abril de 1784, Cruz chegou

\footnotetext{
52 AHU, Cx. 62, doc. 24; Cx. 65, doc. 97; Cx. 73, doc. 36; Cx. 84, doc. 113. Padab, Códice 87A-19-1, Img. 126, 233; Códice 271-C-14-4, Img. 211.

53 ALMEIDA, C. M. C.: "Uma nobreza da terra com projeto imperial. Maximiliano de Oliveira Leite e seus aparentados", in ALMEIDA, C. M. C, J. FRAGOSO, e A. C. J. SAMPAIO: Conquistadores e negociantes. História de elites no Antigo Regime nos Trópicos, Rio de Janeiro: Civilização Brasileira, 2007.
} 
em Luanda ${ }^{54}$, onde, entre 1798 e 1800, fez batizar 2.103 cativos. Parece que sua fortuna foi construída no comércio de cativos em Angola, principalmente em Luanda. Se Cruz começou a atividade tratante ao chegar à cidade em 1784, ele comerciou nela por 16 anos. Levou tempo para ser um dos principais negociantes de cabeças registrados na paróquia dos Remédios em fins dos setecentos. Mas ele, diferente dos Silva Rego e dos Fonseca Coutinho, não era o tipo de negociante que se aliava a redes interioranas pelo parentesco, e transacionava por meio de aviados nos presidios que lhe remetiam cativos porque sua principal base comercial fosse a cidade de Luanda 55 .

Entre os do topo, foi o que menos realizou batismos com mais de 20 cativos. Diferente dele, os filhos da terra, falantes português e de quimbundo, geralmente ocupavam os postos militares necessários ao comércio nos presídios do interior e lidavam com sobados fornecedores de escravos ${ }^{56}$. Não era o caso de Cruz, que se casou com uma portuguesa viúva de um criado do governador português de Angola, Barão de Moçâmedes ${ }^{57}$. Todavia, embora desprovido de patente militar, o cargo de cirurgião mor se ligava aos militares, pois seu ocupante era obrigado a tratar o corpo militar de Angola58. Provavelmente, o cargo o ajudou a criar redes mercantis com participação de militares.

Ao pedir seu retorno a Lisboa em 1795, Cruz alegou doença e que servia em Angola há mais de dez anos, sendo atendido pelo Conselho Ultramarino de Lisboa em 23 de maio de $1796^{59}$. Tudo indica que a partida iminente de Cruz de retorno a Portugal o levou a investir no negócio de cativos recursos acumulados em sua vida em Luanda. Não há certeza se ele saiu da cidade antes dos batismos de suas cabeças deixando um procurador em seu lugar. A única certeza é que, mesmo entre as elites e os do topo do mercado de Luanda, havia diferentes tipos de vendedores de humanos, com distintas formas de acesso às cabeças e de envolvimento em laços pessoais e redes mercantis.

\section{Conclusão}

Corpus documental inexplorado para o estudo do comércio de gente, assentos de batismo de Luanda demonstraram a participação de milhares eventuais e pequenos donos de cabeças lado a lado de poucos negociantes grandes, da elite e do topo que dominavam o grosso do negócio em suas mãos. Por sua vez, recebendo o seu quinhão, os capitães de embarcações que aportaram em

54 Informações sobre Manoel da Cruz provêm de AHU, Cx. 68, docs. 21, 25 e 40; cx. 82, docs. 47, 65. Padab, Códice 258-C-11-5, Img. 390, Códice 285-C-17-4, Img. 153; Códice 290-C-183, Img. 224.

55 CORREA, C. P.: Cambambe, Angola, no contexto do comércio atlântico de escravizados (17901850), Rio de Janeiro: UFRJ-PPGHIS, tese de doutorado, 2019, pp. 216-220.

56 Cf. PANTOJA, S.: O encontro nas terras de além-mar: os espaços urbanos do Rio de Janeiro, Luanda e Iha de Moçambique na era da ilustração, São Paulo: USP-FFLCH, tese de doutorado, 1994; PANTOJA.S.: "Famílias e comércio de escravos...", art. cit., p. 196; COUTO, C.: Os capitães-mores em Angola..., op. cit.; SANTOS, C. M.: Um governo polido..., op. cit.; CARVALHO, A.: Militares e militarização no Reino de Angola..., op. cit..; CARVALHO, A.: Guerras nos sertões de Angola..., op. cit.

57 AHU, Cx. 82, doc. 65.

58 AHU, Cx. 84, doc. 91 e 100

59 AHU, Cx. 82, doc. 65. 
Luanda talvez labutassem mais em prol de terceiros do que de si mesmos, mas ainda assim eram importantes para o negócio. Pode ser que aspectos legais deixassem a cargo dos donos das cabeças, e não dos que as transportavam, o ônus de arcar com os custos do batismo. Isto levaria os padres a registrar com mais frequência os batismos de cabeças pertencentes aos filhos da terra e aos negociantes estabelecidos, mas nós não encontramos indícios na documentação neste sentido. De qualquer modo, aqueles grandes mercadores, da elite e do topo, filhos da terra ou estabelecidos, operavam por meio de associações ou parentesco que os ligavam aos presídios interioranos, como os Fonseca Coutinho, os Silva Rego e os Pereira Bravo, ligações pouco acessíveis a outsiders e a visitadores, ainda que frequentes, das cidades portuárias. Assim, em maior ou menor grau, principalmente os mercadores da elite e os do topo, se filhos da terra ou estabelecidos, se calcavam em seus parentes e/ou em seus aliados nos presídios. Se desprovidos de embarcações, eles dependiam de capitães de navios e/ou de outros homens de negócio de praças em Portugal e no Brasil, em termos operacionais, apenas para a travessia atlântica. Em termos creditícios, decerto também; mas sempre? Talvez não seja o caso, o que outras pesquisas trarão à luz.

Ademais, os cargos e postos administrativos que os filhos da terra e os estabelecidos exerciam indicam seu poder politico e/ou que estavam fortemente neles baseados. Para estes homens, trato de gente, parentesco/aliança e poder andavam juntos. Logo, o comércio de almas girava ao redor da política não apenas em relação às elites africanas ${ }^{60}$. Assim, tudo indica que os que controlavam os fluxos entre as regiões interioranas e as cidades portuárias o faziam por um sistema de crédito (no sentido lato) e por sólidas redes parentais e mercantis pessoalizadas (os afetos), que lhes garantiam o suprimento de cativos e o não cair, ou mesmo quebrar, em tramoias ou reviros, práticas que consistiam em o aviado não entregar os escravos ao credor que lhe adiantou recursos, mas a outros quaisquer comerciantes ${ }^{61}$. Logo, talvez a falta de controle ou de sólidas ligações com os que lidavam com os fluxos de cabeças dos presídios para as cidades litorâneas tornava os comerciantes não estabelecidos, homens de mar em fora, como se dizia, um tanto quanto dependentes do fornecimento de cabeças em Angola. A espera podia ser maior etc.

Fosse como fosse, conquanto se debata se os negociantes de cativos de Luanda e de Benguela eram dependentes de créditos brasileiros ou portugueses, o fato é que havia um sólido grupo mercantil longevo sediado em Luanda, e decerto em Benguela, capaz de se reproduzir no tempo a partir de seus interesses, de seus laços políticos, parentais e creditícios. Concomitantemente, a elite e os do topo criaram e recriaram o mercado de gente ao lado de uma multidão de marinheiros, forros, livres de poucas posses que legitimaram, de baixo para cima, a sociedade traficante alimentada pela escravização e venda de milhares e milhares de cabeças anônimas batizadas em nome de Deus na freguesia de Nossa Senhora dos Remédios.

60 MILLER, J. C.: Way of death: Merchant..., op. cit., capítulo 1.

61 Ibid., pp. 276-277, 470. 


\section{Bibliografia}

ALBUQUERQUE, A. E. B.: De "Angelo dos retalhos" a visconde de Loures: a trajetória de um traficante de escravos (1818-1858). Recife: UFPE-PPGHIS, Dissertação de Mestrado, 2016.

ALMEIDA, C. M. C: "Uma nobreza da terra com projeto imperial. Maximiliano de Oliveira Leite e seus aparentados", in ALMEIDA, C. M. C., J. FRAGOSO, e A. C. J. SAMPAIO: Conquistadores e negociantes. História de elites no Antigo Regime nos Trópicos, Rio de Janeiro: Civilização Brasileira, 2007.

BERGER, I.: "African Women's History: Themes and perspectives", Journal of Colonialism and colonial History, Baltimore, v. 4, n. 1, pp. 1-11, 2003.

BÔSCARO, A. P.: Sociedade Traficante: o comércio interno de escravos no centro-sul brasileiro e suas conexões na primeira metade do século XIX (Juiz de Fora, Minas Gerais). Juiz de Fora, Programa de Pós-Graduação em História, Tese de Doutorado, 2021.

CANDIDO, M. P.: "African women in ecclesiastical documents, Benguela, 1760-1860", Social Sciences and Missions, Leiden, v. 28, n. ${ }^{\text {s }}$ 3-4, 2015, pp. 235-260.

- An African Slaving Port and the Atlantic World. Benguela and its Hinterland. Cambridge: Cambridge University Press, 2013.

CAPELA, J.: Donas, Senhores e Escravos. Porto: Afrontamento, 1996.

CARDOSO, C. A. L.: "Ana Joaquina dos Santos Silva: Industrial Angolana da segunda metade do século XIX", in Boletim Cultural da Câmara Municipal de Luanda, v. 32, 1972, pp. 5-14.

CARVALHO, A.: Militares e militarização no Reino de Angola: patentes, guerra, comércio e vassalagem (segunda metade do século XVIII) Seropédica, Universidade Federal Rural do Rio de Janeiro, Programa de Pós-Graduação em História, Dissertação de Mestrado em História), 2014.

- Guerras nos sertões de Angola: sobas, guerra preta e escravização (17491797), Rio de Janeiro: UFRJ, PPGHIS, tese de doutorado, 2020.

CARVALHO, M. J. M.: "O desembarque nas praias: o funcionamento do tráfico de escravos depois de 1831", in Revista de História (USP), v. 167, 2012, p. 223-260.

CORREA, C. P.: Cambambe, Angola, no contexto do comércio atlântico de escravizados (1790-1850). Rio de Janeiro: UFRJ-PPGHIS, tese de doutorado, 2019.

COSTA e SILVA, A.:. Um rio chamado Atlântico. A África no Brasil e o Brasil na África. Rio de Janeiro: UFRJ/Nova Fronteira, 2003.

COUTO, C.: Os capitães-mores em Angola no século XVIII. Lisboa: Instituto de Investigação Científica de Angola, 1972. 
CURTO, J. C.: Álcool e escravos. O comércio luso-brasileiro do álcool em Mpinda, Luanda e Benguela durante o tráfico atlântico de escravos (c. 14801830) e o seu impacto nas sociedades da África Central Ocidental, Lisboa: Editora Vulgata, 2003, p. 343.

- "As if from a free womb: baptismal manumissions in the Concepcion Parish, Luanda, 1778-1807", Portuguese Studies Review, [s. l.], v. 10, n. ${ }^{\circ}$, 2002, pp. 26-57.

CURTO, J, R. R. GERVASIS. R.: "The Population History of Luanda during the Late Atlantic Slave Trade, 1781-1844", African Economic History, Vol. 29, 2001, pp. 50, 58.

DAVIS, D. B.: O problema da escravidão na cultura ocidental. Rio de Janeiro: Civilização Brasileira, 2000.

ELTIS, D. (2000). The Rise of African Slavery in the Americas. Cambridge, Cambridge University Press, 2000.

ELTIS, D; RICHARDSON. D. (eds.): Extending The Frontiers: Essays on the New Transatlantic Slave Trade Database, New Haven, Yale University Press, 2008.

FERREIRA, R. A.: Dos Sertões ao Atlântico. Rio de Janeiro: UFRJ, PPGHIS, Dissertação de Mestrado, 1997.

-Cross-Cultural Exchange in the Atlantic world: Angola and Brazil during the era of the slave trade. Cambridge: Cambridge U. P., 2002.

FERREIRA, R., e R. GUEDES: "Erasing the note that says slave. Efigênia da Silva, baptism, compadrazgo, names, heads, crias, slave trade, slavery and freedom (Luanda, c. 1770-c. 1811)", in Almanack, 2020.

FINLEY, M. (1991). Escravidão antiga e ideologia moderna. Rio de Janeiro: Graal, 1991.

FLORENTINO, M. G.: Em Costas Negras: uma história do tráfico de escravos entre a África e o Rio de Janeiro, Rio de Janeiro: Arquivo Nacional, 1995.

FRAGOSO, J., e R. GUEDES: "Alegrias e artimanhas de uma fonte seriada. Os códices 390, 421, 424 e 425: despachos de escravos e passaportes da Intendência de Polícia da Corte, 1819-1833, in Botelho, Tarcísio et. al (Orgs.). História Quantitativa e serial no Brasil: um balanço. Goiânia: ANPUH-MG, 2001.

-(2001a). Tráfico de escravos, mercadores e fianças. Dois bancos de dados (despachos de escravos, passaportes e licenças). Códices 390, 411, 419, 421, 424, 425, 1000 e 1002. Relatório de Pesquisa apresentado ao IPEA, $2001 \mathrm{a}$.

GUEDES, R.: "Comércio interno de cativos, grandes traficantes e forros traficantes: o compromisso social com a escravidão, com a desigualdade, e a precariedade de um corpus documental (Sudeste do Brasil, inícios do século XIX)", in Cury, Cláudia et. al (Orgs.). O Império do Brasil: educação, impressos e confrontos sociopolíticos. São Luís: Café \& Lápis/ Editora Uema, 2015, pp. 317-360. 
GUEDES, R., A. P. BÔSCADO: A cara da escravidão e a cara da liberdade: honra e infâmia (Corte do Brasil, 1809-1833), AFRO-ÁSIA (UFBA. IMPRESSO), v. 59, 2019, pp. 197-234.

- "Escravos tropeiros e traficantes de cativos, seus senhores, seus camaradas e seus parceiros (Sul-Sudeste do Brasil, 1809-1833)", in IVO, Isnara, e R. GUEDES (Orgs.): Escravidão: povos, poderes e legados. Américas, Goa e Angola (séculos XVI-XXI), São Paulo: Alameda, 2020, pp. 279-310.

- "O Rio de Janeiro e a reprodução da sociedade escravista: rotas e agentes no comércio interno de cativos entre a corte e São Paulo (1809-1933)", in Arquivo Geral da Cidade do Rio de Janeiro (org.): Escravidão e luta pela liberdade no Rio de Janeiro: histórias, arquivos e patrimônio, Rio de Janeiro: Prefeitura do Rio/AGCRJ, 2020a, pp. 21-56.

KARASCH, M.: A vida dos escravos no Rio de Janeiro (1808-1850). São Paulo, Cia das Letras, 2000.

MAMIGONIAN, B. G.: Africanos Livres: a abolição do tráfico de escravos no Brasil. São Paulo: Companhia das Letras, 2017.

MARCILIO, M. L.: Crescimento demográfico e evolução agrária paulista (17001836). São Paulo: Hucitec, 2000.

MARCUSSI, A (2013). O dever catequético: a evangelização dos escravos em Luanda nos séculos XVII e XVIII, Revista 7 Mares, Niterói, n. ${ }^{\circ}$ 2, 2013, pp. 64-79.

MARTINS, R.: Crescendo em silêncio. A incrivel economia escravista de Minas Gerais no século XIX. Belo Horizonte: ICAM/ABPHE, 2018.

MEILLASSOUX, C.: Antropologia da escravidão: o ventre de ferro e o dinheiro, Rio de Janeiro: Zahar, 1996.

MEMEL-FÔTE, H.: L'esclavage dans les sociétés lignagères de l'Afrique noire. Exemple de la Côte d'Ivoire précoloniale, 1700-1920, thèse (pour le doctorat d'État ès lettres et sciences humaines), Paris: École des Hautes Etudes en Sciences Sociales, 1988.

MILlER, J. C. : Way of Death. Merchant Capitalism and the Angolan Slave Trade, 1730-1830. Wisconsin, Wisconsin University Press, 1988.

OLIVEIRA, M. R.: Divisão Naval da Costa d'Leste: a expansão da Guerra Ciplatina para o litoral africano (1825-1830). Seropédica, UFRRJ-PPHR. Diss. de Mestrado, 2017.

OLIVEIRA, V. S.: The Donas of Luanda, c. 1770-1867: from Atlantic Slave Trading to "Legitimate" Commerce, Toronto, York University, Dissertation (Doctor of Philosophy), 2016.

ORIOLI, J. P.: "Trajetórias, mobilidade social e comércio no Atlântico no século XVIII: o padre angolano Lourenço da Costa de Almeida e seus familiares", Temporalidades, Revista de História, 2018. 
PANTOJA, S.: O encontro nas terras de além-mar. os espaços urbanos do Rio de Janeiro, Luanda e Iha de Moçambique na era da ilustração, São Paulo: USP-FFLCH, tese de doutorado, 1994.

- "Gênero e comércio: as traficantes de escravos na região de Angola", Travessias. Revista de Ciências Sociais e Humanas em Lingua Portuguesa, n. ${ }^{\circ}$ 4/5, Lisboa, 2004.

- "Laços de afeto e comércio de escravos. Angola no século XVIII", Cad. Pesq. Cdhis, Uberlândia, v.23, n.2, jul./dez., 2010

— "Famílias e comércio de escravos: Angola século XVIII", Cadernos de Pesquisa do CDHIS (UFU. Impresso), v. I, pp. 23-42, $2010^{\mathrm{a}}$.

- "Entre Luanda e Rio de Janeiro: o padre, o bispo e o coronel», Ibid e Thompson, Estevem C. Em torno de Angola: narrativas, identidades e as conexões atlânticas. São Paulo: Intermeios, pp. 87-109, 2014.

POLANYI, K.: A grande transformação. Rio de Janeiro: Campus, 2002.

REGINALDO, L.: "Rosários dos pretos, "São Benedito de Quissama”: irmandades e devoções negras no mundo atlântico (Portugal e Angola, século XVIII)", Studia Historica, História Moderna, v. 38, n. ${ }^{\circ}$ 1, 2016, pp. 123-151.

SANTOS, C. M.: Um governo polido para Angola, Lisboa/Paris: UNL/EHESS, Tese de Doutorado, 2005.

SANTOS, M. E. M.: "África; Angola", in AZEVEDO, C. M. de (dir.): Dicionário de história religiosa de Portugal, Lisboa: Círculo de Leitores, 2000, pp. 21-25, 51-67.

SILVA, D. B. D.: "The Supply of Slaves from Luanda, 1768-1806: Records of Anselmo da Fonseca Coutinho", African Economic History, v. 38, 2010, pp. 53-76.

SPARKS, R. J. (2014). Where the Negroes Are Masters. An African Port in the Era of the Slave Trade. Cambridge, Massachusetts, and London, England: Harvard University Press.

STILWELL, S.: Slavery and Slaving in African History. Cambridge: Cambridge U. P., 2014.

THOMPSOM, E.: Familias traficantes nas rotas entre Angola e Brasil em fins do século XVIII. Brasília: UNB, Programa de Pós-Graduação em História, Dissertação de mestrado, 2006.

THORNTON, J. K.: "Central African names and African-American naming patterns", The William and Mary Quarterly, Williamsburg, v. 50, n. 4, 1993, pp. 727-742.

- "Sexual demography: the impact of the slave trade on family structure", in: Robertson, Claire; Klein, Martin (ed.). Women and slavery in Africa. Madison: University of Wisconsin Press, 1983.

VERGER, P.: Fluxo e refluxo do tráfico de escravos entre o Golfo de Benin e a Bahia de Todos os Santos. São Paulo: Corrupio, 1987. 
VIDE, Sebastião Monteiro da (1720): Constituições Primeiras do Arcebispado da Bahia, Coimbra, Real Colégio das Artes e da Companhia de Jesus. Brasil, Brasília, Edição do Senado Federal, 2007.

WEBER, P. M.: “Angola” como conceito: uma análise da obra história geral das guerras angolanas Oliveira de Cadornega (século XVII). Porto Alegre: PUCRS, Programa de Pós-Graduação em História, Tese de Doutorado, 2018.

WHEELER, D. L.: Angolan Woman of Means: D. Ana Joaquina dos Santos e Silva, Mid-Nineteenth Century Luso-African Merchant-Capitalist of Luanda. In: Santa Barbara Portuguese Studies Review, v. 3, 1996, pp. 284-297.

XIMENES, C. F L.: Bahia e Angola: redes comerciais e o tráfico de escravos (1750-1808). Niterói: UFF-PPGHIS, tese de doutorado, 2012. 


\section{Apêndice}

Quadro 4: Topo, elite e grandes donos de cabeças (Freguesia de Nossa Senhora dos Remédios, 17981804)

\begin{tabular}{|c|c|c|c|c|c|c|c|c|c|c|}
\hline $\mathbf{N}$ & Nome & 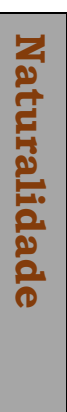 & 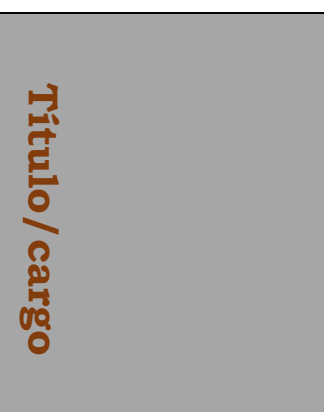 & 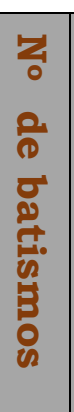 & 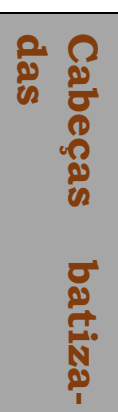 & 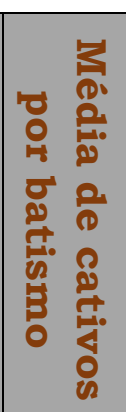 & 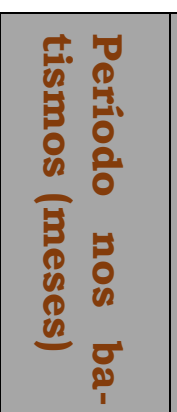 & $\begin{array}{l}\text { Estima- } \\
\text { tiva de } \\
\text { periodo } \\
\text { minimo } \\
\text { de ope- } \\
\text { ração } \\
\text { em } \\
\text { Luanda }\end{array}$ & 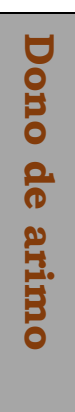 & 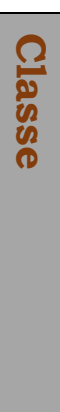 \\
\hline \multicolumn{11}{|c|}{ Filhos da terra e estabelecidos oriundos de Portugal ou do Brasil } \\
\hline 1 & 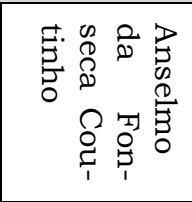 & $\begin{array}{l}5 \\
5 \\
0 \\
0 \\
0 \\
0\end{array}$ & 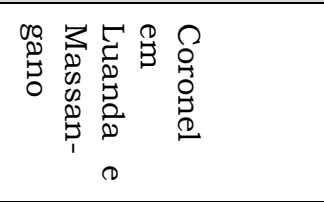 & $\vec{w}$ & $\begin{array}{l}\omega \\
\stackrel{y}{ } \\
\text { J }\end{array}$ & $\begin{array}{l}N \\
\infty \\
\sigma\end{array}$ & 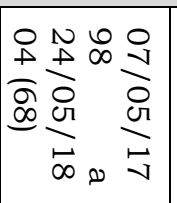 & 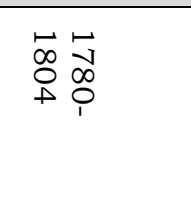 & $\mathscr{Q}$ & $\overrightarrow{0}$ \\
\hline 2 & 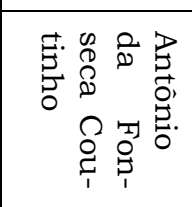 & 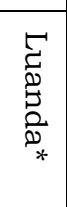 & 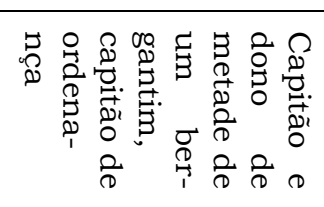 & $\stackrel{N}{\omega}$ & $\begin{array}{l}\text { वृ } \\
\text { वे }\end{array}$ & $\begin{array}{l}N \\
\infty \\
a\end{array}$ & 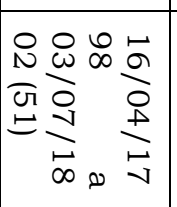 & 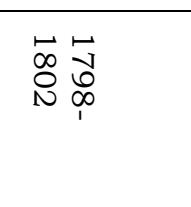 & & 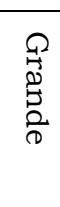 \\
\hline 3 & 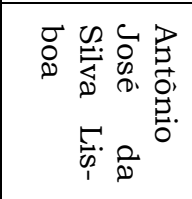 & & 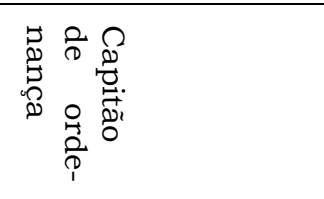 & $\stackrel{\vec{N}}{\vec{N}}$ & $\begin{array}{l}+\overrightarrow{0} \\
\dot{\infty} \\
\stackrel{J}{J}\end{array}$ & $\begin{array}{l}\vec{d} \\
\mathrm{c} \\
\mathrm{cr}\end{array}$ & 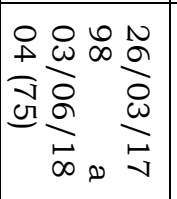 & 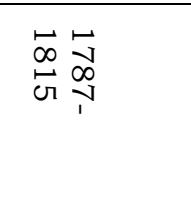 & & $\overrightarrow{0}$ \\
\hline 4 & 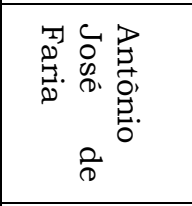 & & 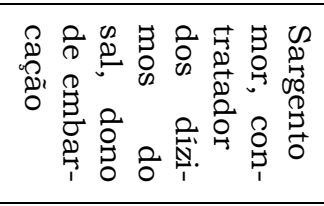 & $\vec{\omega}$ & N & $\begin{array}{l}0 \\
\infty\end{array}$ & 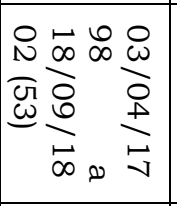 & 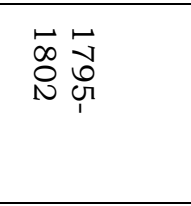 & & $\begin{array}{l}0 \\
0 \\
0 \\
0 \\
0 \\
0\end{array}$ \\
\hline 5 & 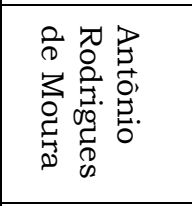 & $\begin{array}{l}5 \\
5 \\
0 \\
0 \\
0 \\
0\end{array}$ & 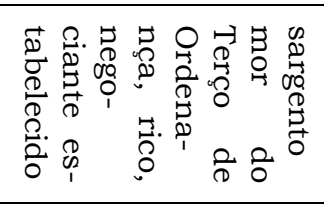 & N & $\begin{array}{l}\stackrel{2}{\infty} \\
\infty\end{array}$ & $\begin{array}{l}\omega \\
\omega \\
0\end{array}$ & 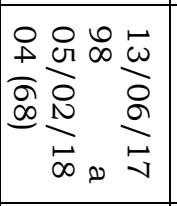 & 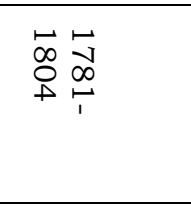 & & 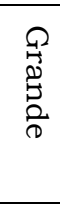 \\
\hline 6 & 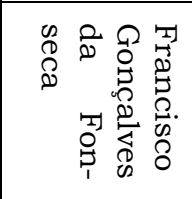 & & 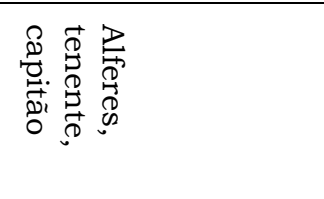 & $\vec{b}$ & $\begin{array}{l}w \\
\tilde{N} \\
\sigma\end{array}$ & $\stackrel{v}{\omega}$ & 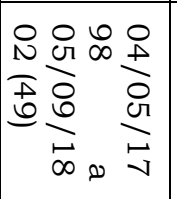 & 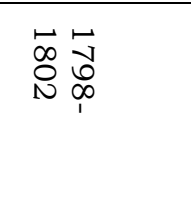 & & $\begin{array}{l}\Omega \\
0 \\
\underbrace{2} \\
0 \\
0\end{array}$ \\
\hline 7 & 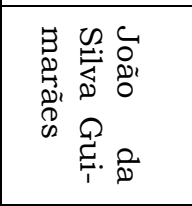 & $\begin{array}{l}\overrightarrow{5} \\
\stackrel{2}{2} \\
\mathscr{D}_{0} \\
*\end{array}$ & 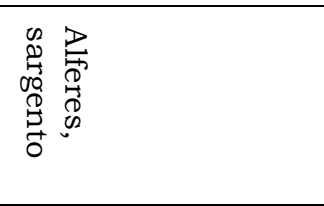 & $+\infty$ & $\begin{array}{l}\omega \\
\text { o }\end{array}$ & $\stackrel{a}{a}$ & 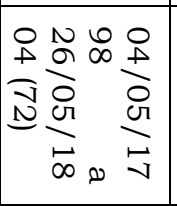 & 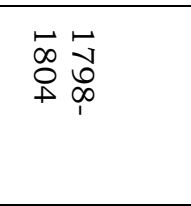 & & $\begin{array}{l}2 \\
0 \\
\underbrace{2} \\
0 \\
0\end{array}$ \\
\hline 8 & 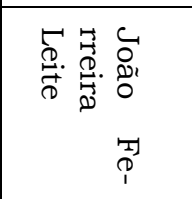 & & 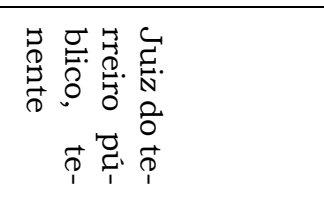 & $\stackrel{\omega}{v}$ & ¿ & $\begin{array}{l}N \\
+ \\
+\end{array}$ & 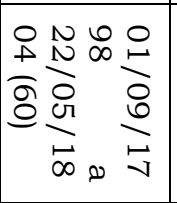 & 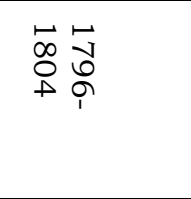 & $\stackrel{\Xi}{5}$ & 罯 \\
\hline
\end{tabular}




\begin{tabular}{|c|c|c|c|c|c|c|c|c|c|c|}
\hline 9 & 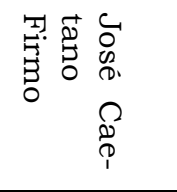 & 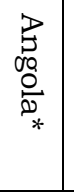 & 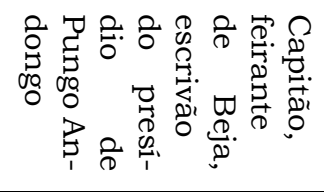 & • & $\underset{\sigma}{\sigma}$ & $\stackrel{\vec{N}}{\stackrel{N}{N}}$ & 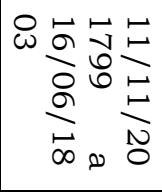 & 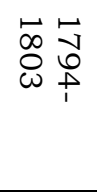 & & $\begin{array}{l}\text { वै } \\
0 \\
0 \\
0 \\
0\end{array}$ \\
\hline 10 & 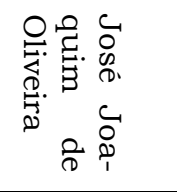 & & 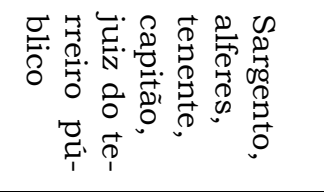 & $\underset{v}{N}$ & $\stackrel{\omega}{\sigma}$ & $\Xi$ & 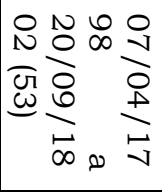 & 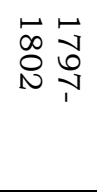 & & $\begin{array}{l}\text { Q } \\
\text { कै } \\
0 \\
0\end{array}$ \\
\hline 11 & 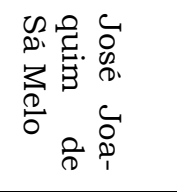 & & 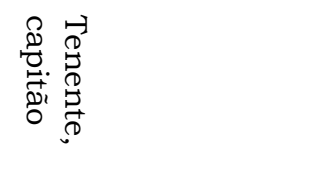 & $\begin{array}{c}N \\
\mathcal{N}\end{array}$ & $\begin{array}{l}\omega \\
\stackrel{A}{N}\end{array}$ & $\underset{v}{\vec{\omega}}$ & 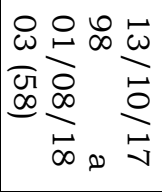 & 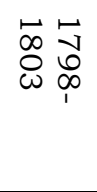 & & $\begin{array}{l}\text { की } \\
\text { है } \\
\text { के }\end{array}$ \\
\hline 12 & 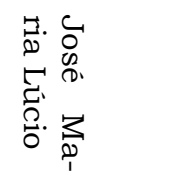 & 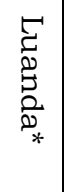 & 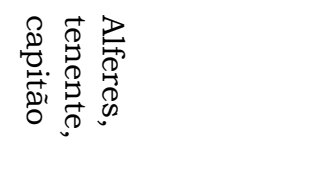 & $\begin{array}{l}N \\
\mathcal{N}\end{array}$ & $\begin{array}{l}w \\
N\end{array}$ & $\underset{\omega}{\vec{\omega}}$ & 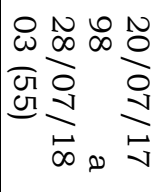 & 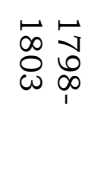 & & $\begin{array}{l}\text { की } \\
\text { है } \\
\text { مे }\end{array}$ \\
\hline 13 & 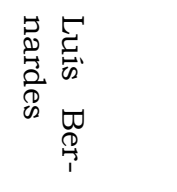 & 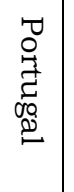 & 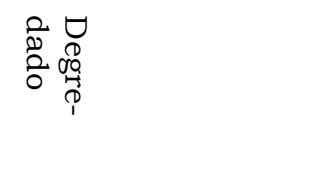 & $\stackrel{N}{\sim}$ & $\begin{array}{l}\omega \\
\tilde{O} \\
0\end{array}$ & $\vec{\jmath}$ & 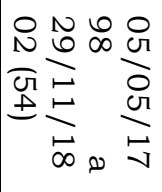 & $\underset{\infty}{\vec{\infty}} \underset{N}{\stackrel{D}{N}}$ & & $\begin{array}{l}\text { की } \\
\text { है } \\
\text { مे }\end{array}$ \\
\hline 14 & 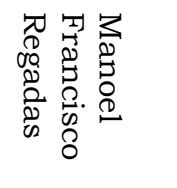 & & 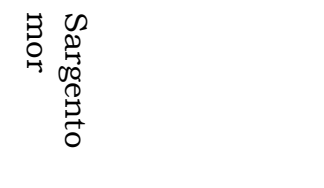 & $\mathcal{G}$ & $\underset{\perp}{N}$ & $\underset{\stackrel{\omega}{\omega}}{\vec{\omega}}$ & 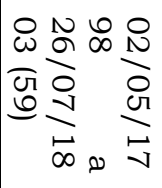 & 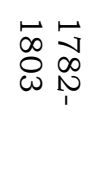 & $\stackrel{\mathscr{D}}{\Xi}$ & $\stackrel{\text { 말 }}{\overrightarrow{0}}$ \\
\hline 15 & 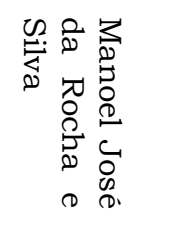 & 垔 & 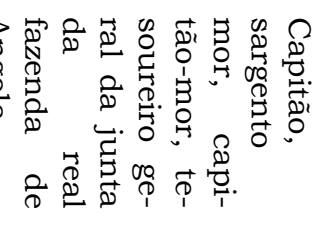 & $\underset{\infty}{N}$ & जુ & $\stackrel{N}{N}$ & 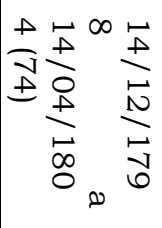 & $\begin{array}{l}\overrightarrow{1} \\
\infty \\
0 \\
1 \\
\vdots \\
\infty \\
0 \\
+\infty\end{array}$ & $\stackrel{\mathscr{Q}}{5}$ & $\stackrel{\text { 딸 }}{\overrightarrow{0}}$ \\
\hline 16 & 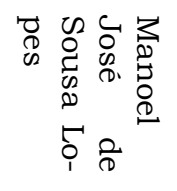 & & 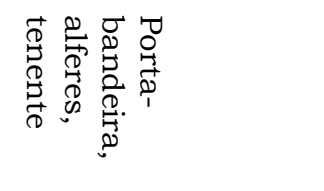 & के & $\begin{array}{l}\overrightarrow{0} \\
\infty \\
\infty\end{array}$ & $\underset{\omega}{\vec{\omega}}$ & 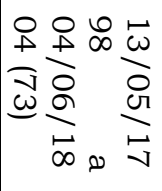 & 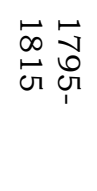 & $\frac{2}{5}$ & क्ष \\
\hline 17 & 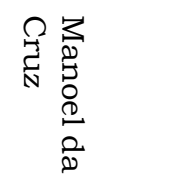 & 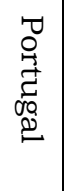 & 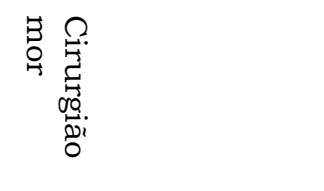 & $\ddot{\circ}$ & $\begin{array}{l}\stackrel{N}{\dot{O}} \\
\dot{\omega}\end{array}$ & $\begin{array}{l}\overrightarrow{0} \\
\infty\end{array}$ & 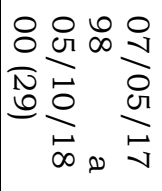 & 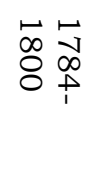 & & - \\
\hline 18 & 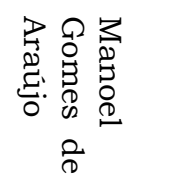 & & $\begin{array}{rl}3 & 0 \\
0 & 0 \\
0 & 0 \\
0 & 0 \\
0 & 0 \\
0 & 0 \\
0 & 0 \\
0 & 0 \\
0\end{array}$ & Uv & $\dot{8}$ & $\begin{array}{l}\tilde{\omega} \\
\omega \\
\omega\end{array}$ & 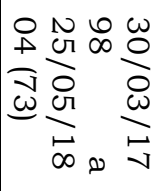 & 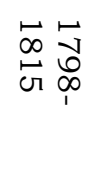 & $\stackrel{D}{5}$ & 离 \\
\hline 19 & 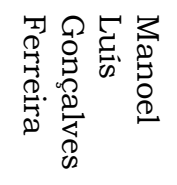 & 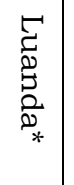 & 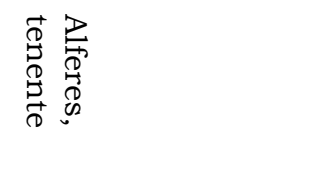 & No & $\begin{array}{l}\pi \\
\infty \\
\sim\end{array}$ & 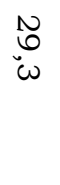 & 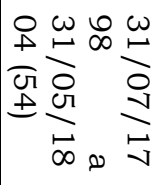 & 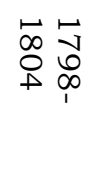 & & $\begin{array}{l}\text { Q } \\
\text { है } \\
0 \\
0\end{array}$ \\
\hline
\end{tabular}


Cabeças: disseminação, desigualdade e concentração...

\begin{tabular}{|c|c|c|c|c|c|c|c|c|c|c|}
\hline 20 & 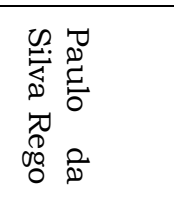 & & 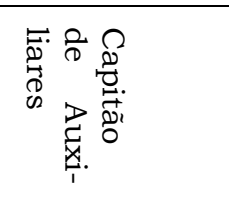 & $\stackrel{N}{\sqcup}$ & N & 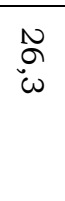 & 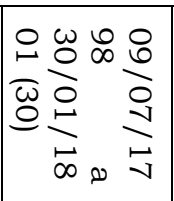 & 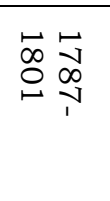 & & 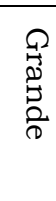 \\
\hline 21 & 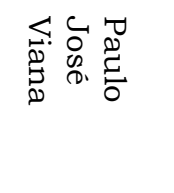 & & 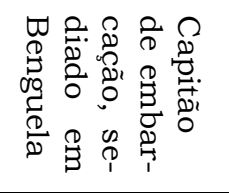 & $\sqsupset$ & $\underset{\omega}{\omega}$ & $\begin{array}{l}\omega \\
\infty \\
\infty \\
\infty\end{array}$ & 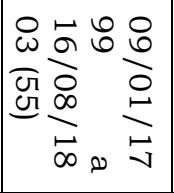 & 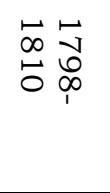 & & $\begin{array}{l}\text { Q } \\
\text { है } \\
\text { के }\end{array}$ \\
\hline 22 & 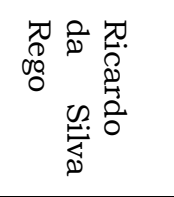 & & 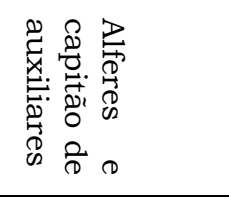 & $\stackrel{v}{+}$ & $\begin{array}{l}N \\
+ \\
\dot{D} \\
\infty\end{array}$ & $\begin{array}{c}\omega \\
\omega \\
+ \\
+\infty\end{array}$ & 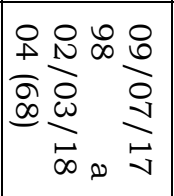 & 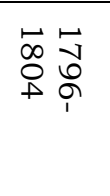 & $\frac{0}{5}$ & $\overrightarrow{8}$ \\
\hline 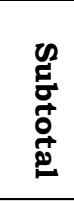 & & & & $\begin{array}{l}+ \\
\dot{0} \\
:\end{array}$ & $\begin{array}{l}N \\
N \\
\dot{D} \\
\infty \\
\infty\end{array}$ & $\stackrel{\text { in }}{N}$ & & & & \\
\hline \multicolumn{11}{|c|}{ Capitães de Embarcações } \\
\hline$\stackrel{N}{\omega}$ & 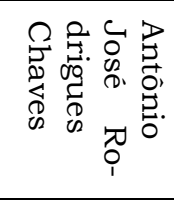 & & 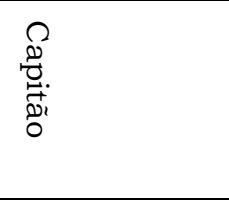 & $v$ & $\begin{array}{l}\omega \\
\omega \\
\omega\end{array}$ & I & 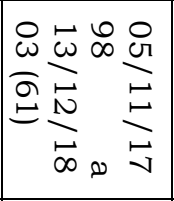 & 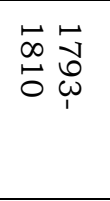 & & $\begin{array}{l}\text { Q } \\
0 \\
0 \\
0 \\
0\end{array}$ \\
\hline$\underset{+}{N}$ & 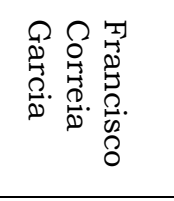 & & 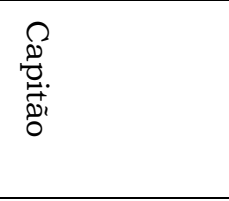 & $\underset{N}{N}$ & $\underset{\omega}{\omega}$ & $\underset{\sim}{u}$ & 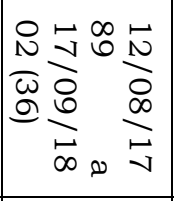 & 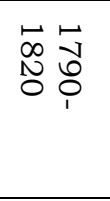 & & $\begin{array}{l}\text { वृ } \\
0 \\
0 \\
0\end{array}$ \\
\hline $\mathcal{N}_{\mathcal{N}}^{N}$ & 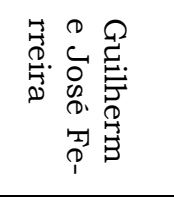 & 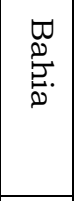 & 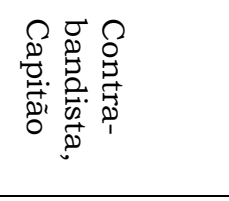 & : & $\begin{array}{l}\omega \\
\stackrel{D}{D} \\
\omega\end{array}$ & $\begin{array}{l}\infty \\
+ \\
\text { or }\end{array}$ & 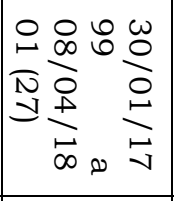 & 蜜 & & $\begin{array}{l}0 \\
0 \\
0 \\
0 \\
0\end{array}$ \\
\hline N & 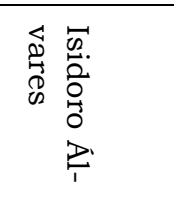 & & 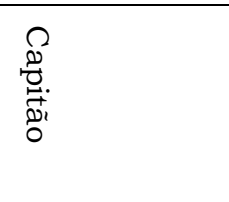 & $a$ & $\begin{array}{l}\omega \\
o \\
\sigma\end{array}$ & $\stackrel{\sigma}{\stackrel{\sigma}{\sigma}}$ & 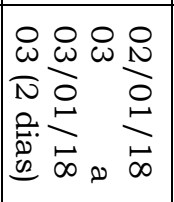 & 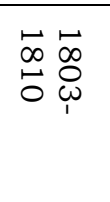 & & $\begin{array}{l}\text { Q } \\
0 \\
0 \\
0 \\
0\end{array}$ \\
\hline N & 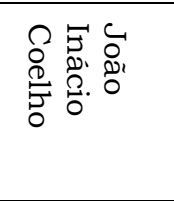 & & 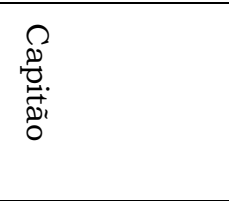 & $\begin{array}{l}w \\
\sigma\end{array}$ & $\stackrel{\circ}{\bullet}$ & $\begin{array}{l}N \\
N \\
w \\
\omega\end{array}$ & 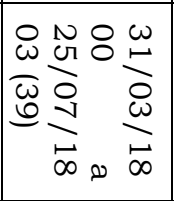 & 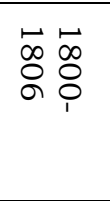 & & 装 \\
\hline$N$ & 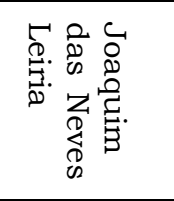 & & 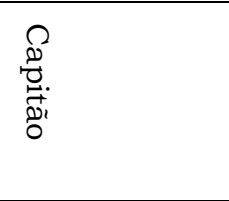 & $\vec{r}$ & $\begin{array}{c}\omega \\
\omega \\
\sim \\
\sim\end{array}$ & $\begin{array}{l}N \\
N \\
\omega\end{array}$ & 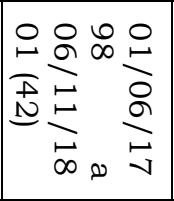 & 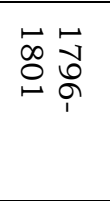 & & $\begin{array}{l}\text { Q } \\
0 \\
0 \\
0 \\
0\end{array}$ \\
\hline N & 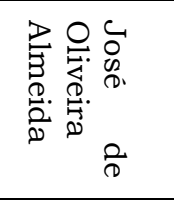 & & 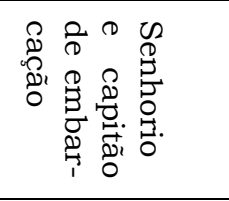 & $\tilde{\omega}$ & $\stackrel{\vartheta}{\Xi}$ & $\underset{v}{u}$ & 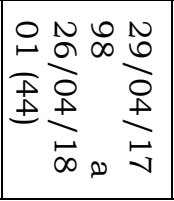 & 崖苞 & & $\begin{array}{l}\text { Q } \\
\text { है } \\
\text { के }\end{array}$ \\
\hline
\end{tabular}




\begin{tabular}{|c|c|c|c|c|c|c|c|c|}
\hline$\ddot{\circ}$ & 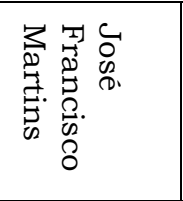 & 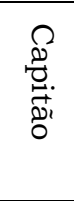 & $\underset{\omega}{N}$ & $\begin{array}{c}N \\
心 \\
\omega\end{array}$ & $\begin{array}{l}n \\
\text { N } \\
0\end{array}$ & 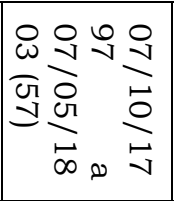 & 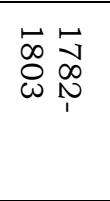 & 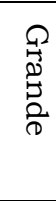 \\
\hline$\stackrel{\omega}{\omega}$ & 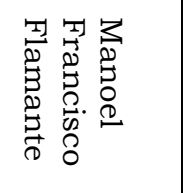 & 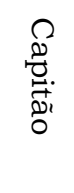 & $\Xi$ & $\underset{\omega}{\omega}$ & $\begin{array}{l}\omega \\
O \\
0\end{array}$ & 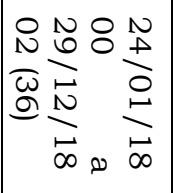 & 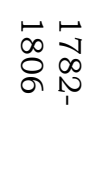 & 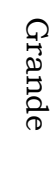 \\
\hline$\underset{N}{\omega}$ & 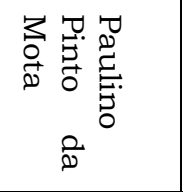 & 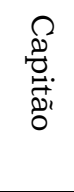 & $\stackrel{t}{0}$ & $\underset{\nu}{\nu}$ & 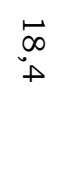 & 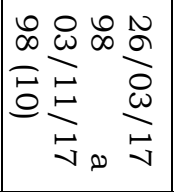 & 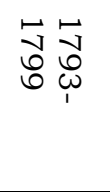 & $\begin{array}{l}\text { 펄 } \\
\text { 랑 }\end{array}$ \\
\hline$\underset{\omega}{\omega}$ & 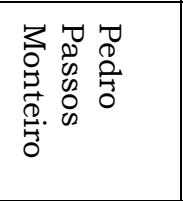 & 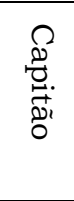 & $\vec{f}$ & $\begin{array}{l}\text { on } \\
\text { ct }\end{array}$ & $\begin{array}{l}\omega \\
\infty \\
\infty \\
0\end{array}$ & 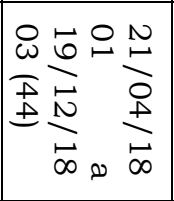 & 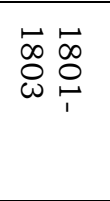 & 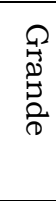 \\
\hline$\underset{+}{\omega}$ & 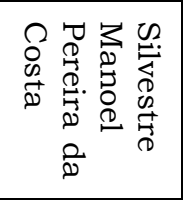 & 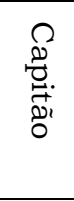 & $\vec{\omega}$ & $\stackrel{\omega}{\sigma}$ & $\stackrel{v}{N}$ & 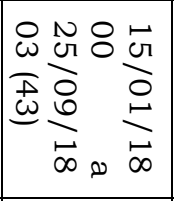 & 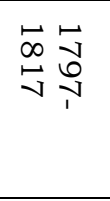 & $\begin{array}{l}\overbrace{0}^{2} \\
\frac{0}{2} \\
0\end{array}$ \\
\hline \multicolumn{3}{|l|}{$\begin{array}{l}0 \\
\vdots \\
\vdots \\
0 \\
0 \\
0 \\
0\end{array}$} & Nั & 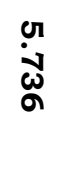 & 出 & & & \\
\hline \multicolumn{9}{|c|}{$\begin{array}{l}\text { Não localizados no TSTD, no Padab, no AHU, em outros documentos e } \\
\text { desprovidos de patentes de tropas locais }\end{array}$} \\
\hline$\underset{\sim}{\omega}$ & 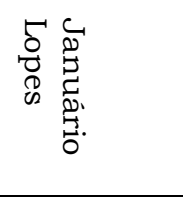 & & 5 & $\begin{array}{l}\underset{N}{W} \\
\text { W }\end{array}$ & $\begin{array}{l}\underset{N}{\omega} \\
\stackrel{\omega}{0}\end{array}$ & 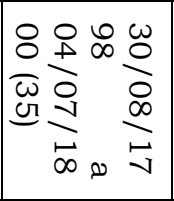 & 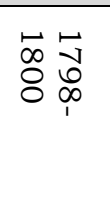 & 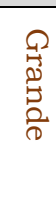 \\
\hline$\omega_{\sigma}$ & 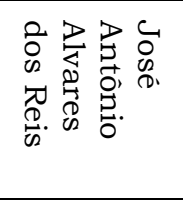 & & N & $\begin{array}{l}\omega \\
\omega \\
\sim\end{array}$ & $\begin{array}{l}\vec{f} \\
0\end{array}$ & 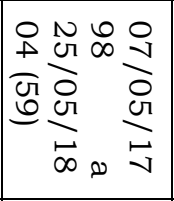 & 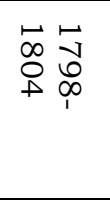 & 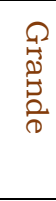 \\
\hline$\underset{v}{w}$ & 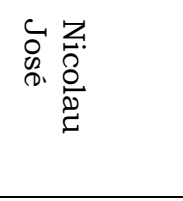 & & $\underset{N}{\omega}$ & $\begin{array}{l}\text { r) } \\
\vec{b}\end{array}$ & $\underset{N}{\vec{N}}$ & 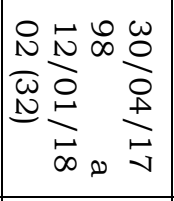 & 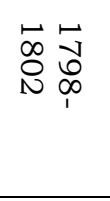 & 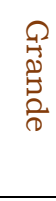 \\
\hline$\omega_{\infty}^{\infty}$ & 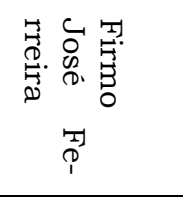 & & $\stackrel{+}{\infty}$ & $\begin{array}{l}\text { Uv } \\
\text { जr }\end{array}$ & $\begin{array}{l}\vec{N} \\
0\end{array}$ & 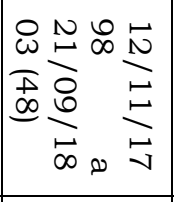 & 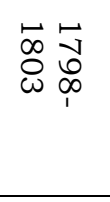 & 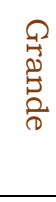 \\
\hline \multicolumn{3}{|l|}{ 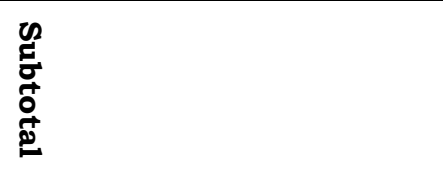 } & 点 & $\begin{array}{l}\dot{\infty} \\
\dot{\infty} \\
\dot{\phi}\end{array}$ & $\stackrel{\vec{c}}{v}$ & & & \\
\hline
\end{tabular}


Fontes para a montagem do quadro indicadas entre parênteses e em ordem alfabética:

(1) Anselmo da Fonseca Coutinho (SILVA, D. B. D.:. The Supply of Slaves from Luanda, 1768-1806, 2010: Records of Anselmo da Fonseca Coutinho. African Economic History v. 38, p. 55. PANTOJA. S.: Entre Luanda e Rio de Janeiro: o padre, o bispo e o coronel. Ibid e THOMPSON, E. C. Em torno de Angola: narrativas, identidades e as conexões atlânticas. São Paulo: Intermeios, pp. 87-109. BML, Manuscritos, Códice $21 \mathrm{~s} / \mathrm{p}$. Fonte, 2014; AHU, Cx. 63 doc. 43 , 47, Cx. 72 doc. 54, Cx. 83, doc. 29, Cx. 83 doc. 68, Cx. 84, doc. 119 , Cx. 85 doc. 20, 29, Cx. 86 doc. $6,8,9,11,13,14,15,18$, Cx. 91 doc. 56, 64. Padab Códice 254 -C-11-1 Img 173, 283, 286, 354). (2) Antônio da Fonseca Coutinho, AHU, Cx. 90 doc. 56; Cx. 63 doc. 47, Cx. 93 doc. 34; cx. 93-A doc. 51. (3) Antônio José da Silva Lisboa (Arquivo Nacional da Torre do Tombo/ANTT, Microfilme 132; AHU, Cx. 76 doc. 9 , Cx. 75 doc. 30, Cx. 76 doc. 86; Padab, Códice 5-A-1-5 Img 489, Códice 258C-11-5 Img 128, 328; TSTD, Viagens 47722, 48478). (4) Antônio José de Faria (AHU, Angola, Cx. 81 docs. 52 e 43; Padab, Códice 256-C-11-3 Imgs 322, 423, 448, Códice 258-C-11-5 Imgs 269, 372), (5) Antônio Rodrigues de Moura (AHU, Cx. 82 doc. 67, Cx. 87 docs. 32, 69, Cx. 89 doc. 23; Padab, Códice 254 -C-11-1 Img 156, 334). (6) Francisco Gonçalves da Fonseca (AHU, Cx. 85 doc. 10, Cx. 89 doc. 32). (7) João da Silva Guimarães (Padab, Códice 258-C-11-5 Img 265). (8) João Ferreira Leite (AHU, Cx. 89 doc. 24; Padab, Códice 290-C-18-3 Img 200, 219). (9) José Caetano Firmo (Códice 87-A-19$1 \mathrm{Img} 401,438$ ). (10) José Joaquim de Oliveira (AHU, Cx. 85 doc. 6; Padab, Códice 258-C-11-5 Img 6, 72; Códice 292-C-18-5 Img 493). (11) José Joaquim de Sá Melo (pela patente militar). (12) José Maria Lúcio (pela patente militar). (13) Luís Bernardes (Padab, Códice 254-C-11-1 Img 230). (14) Manoel Francisco Regadas (ANTT, http:/ / digitarq.arquivos.pt/details?id=7637107; AHU, Cx. 67 doc. 6, Cx. 66 doc. 23, Cx. 75 doc. 24, Cx. 81 doc. 42 e 43; Padab, Códice 258-C-11-5 Img 368, 372; BML, Manuscritos, códice $21 \mathrm{~s} / \mathrm{p}$, Códice 24, fls 97 103V, $115 \mathrm{~V}, 122$ ). (15) Manoel José da Rocha e Silva (AHU, Cx. 73 docs. 1, 35, Cx. 89 doc. 26, Cx. 90 doc. 61, Cx. 92 doc. 36; Padab, Códice 273-C-15-2 Img 472, 474, 481, 486, Códice 254-C-11-1 Img 48, 334, Códice 258-C-115 Img 238, Códice 258-C-11-5 Img 327), (16) Manoel José de Sousa Lopes (AHU, Cx. 84 doc. 102, BML, Códice 28 vol 2, s/p, Códice 24, fl. 157v). (17) Manoel da Cruz (AHU, Cx. 68 docs. 21, 25 e 40; Cx. 82 docs. 47, 65. Padab, Códice 258-C-11-5 Img 390, Códice 285-C-17-4 Img 153; Códice 290-C-18-3 Img 224, CORREA, Carolina Perpétuo. Cambambe, Angola, no contexto do comércio atlântico de escravizados, 1790-1850. Rio de Janeiro: UFRJ-PPGHIS, Tese de Doutorado, 2019, p.217-219). (18) Manoel Gomes de Araújo (BML, Manuscritos, Códice 28, Vol 2; Padab, Códice 258-C-11-5 Img 307, Códice 90-A-19-4 Img 465; ANTT, FF, JU, África, Maço 2, número 2, Ano de 1816; CORREA, Cambambe, 2019, p.217-219). (19) Manoel Luis Gonçalves Ferreira (pela patente militar). (20) Paulo da Silva Rego (AHU, Cx. 73 doc. 36, Cx. 81 doc. 42 e 43, Padab Códice 87-A-19-1 Img 233). (21) Paulo José Viana (AHU, Cx. 74 doc. 58; Padab, Códice 247C-9-4 Img 235, Códice 256-C-11-3 Img 300, 303). (22) Ricardo da Silva Rego (AHU, Cx. 84 doc. 113; Padab, Códice 258-C-11-5 Img 368, 372). (23) Antônio José Rodrigues Chaves (AHA, Padab, IHGB, Códice 314-D-1-3 Imgs 22, 24; Códice 247-C-9-4 Imgs 216 e 250. TSTD, Viagens 19016, 19035, 19082, 19096, 19115, 19138, 19188, 19209, 19248, 19269, 19299, 19361, 8350, 8360, 8401, 40133, 40158). (24) Francisco Correia Garcia (AHA, Padab, IHGB, códice 247-C-9-4 Imgs 228 e 237; TSTD, Viagens 8324, 8336, 8351, 8364, 48745, 40479, 19032, 19054, 19071, 40043, 19136, 19162, 19216, 19239, 19259, 19295, 19338, 7063, 7264, 7390, 7175, 91, 49029). (25) Guilherme José Ferreira (AHU, Cx. 90 doc. 65; cx. 91 doc. 1; Padab, Códice 247-C-94 Img 77, 86, 104; Códice 256-C-11-3 Img 448; TSTD Viagens 40057, 40101). (26) Isidoro Álvares (TSTD, Viagens 19293, 19321, 19359). (27) João Inácio Coelho (TSTD, Viagens 40182, 40039, 40039). (28) Joaquim das Neves Leiria (Padab, Códice 315 -D1-4 Img 25, Códice 256-C-11-3 Img 448, 453; TSTD, Viagens 19023, 8389, 8404, 19074, 19091, 19109, 19141). (29) José de Oliveira Almeida (Padab, Códice 314-D-1-3 Imgs 8 e 28; TSTD, Viagens 40326 e 48540.) (30) José Francisco Martins (AHU, cx. 67 doc. 3; cx. 84 doc. 15, 16, 20. TSTD, Viagens 19030, 19079, 19097, 19175, 19717, 8342, 8352, 8362, 8416, 4842 1, 48443, 19006. Padab, Códice 273-C-15-2 Img 423; Códice 314-D1-3 Img 25, 29; Códice 256-C-11-3 Img 283, 296). (31) Manoel Francisco Flamante 
(AHU, cx. 79 doc. 14 e 25 , cx. 80 doc. $40,8,15,43,58$; cx. 81 doc. 6 , cx. 82 doc. 17 , cx. 91 doc. 18. Códice 283-C-17-2 Img 181, Códice 273-C-15-2 Img 288, Códice 314D-1-3 Img 17. TSTD, Viagens 8253, 8269, 8273, 8278, 48405, 8290, 8302, 8312, 8335, 46803, 8126, 48500, 48770, 48518, 40083, 48534). (32) Paulino Pinto da Mota (AHU, Cx. 89 doc. 49, Padab Códice 273-C-15-2 Img 238, Códice 314-D-1-3 Img 22, Códice 254 -C-11-1 Img 269. TSTD Viagens 8110, 48480). (33) Pedro Passos Monteiro (TSTD Viagens 19133, 47272, 49436, 49448, 49664, 48338, 48358). (34) Silvestre Manoel Pereira da Costa (Códice 247-C-9-4 Img 258, 272; TSTD Viagens 167, 378, 8417, 40037, $40081,47317,47318,47719,49795,48506,48583,48622,49028,8436) .35$ a 38 localizados apenas nos registros de batismo. 